\title{
Oxygen-Containing Nanoclusters on the Surface of Pt-Electrodes and Oxygen Reduction Reaction in Alkaline Medium
}

\author{
Aleksey M. Trunov \\ Odessa National Maritime University, Mechnikova 34, Odessa, UA 65029, Ukraine \\ Correspondence should be addressed to Aleksey M. Trunov; trunov_am@paco.net
}

Received 25 January 2018; Accepted 1 April 2018; Published 4 June 2018

Academic Editor: Samson Khene

Copyright (C) 2018 Aleksey M. Trunov. This is an open access article distributed under the Creative Commons Attribution License, which permits unrestricted use, distribution, and reproduction in any medium, provided the original work is properly cited.

\begin{abstract}
Analysis of the role of oxygen-containing nanoclusters in oxygen reduction reaction (ORR) on Pt-electrodes in alkaline media is provided on the basis of the concept of electrochemical processes with slowed stage of consecutive heterogeneous chemical reaction (ConHCR). Under the ConHCR concept, the main factor determining the ORR characteristics is energetic inhomogeneity of electrode surface (EIES) according to Temkin. A new concept, according to which EIES is determined by the Gibbs energy of formation of oxygen-containing surface structures with inclusions of surface defects of the platinum crystal structure, ${ }_{s, \mathrm{~d}} \mathrm{Pt}$, is formulated. A correlation between the level of EIES of Pt-electrodes and packing density of ${ }_{s, d} \mathrm{Pt}$ atoms on the surface of Pt(hkl) monocrystals is determined. The concept, according to which the stationary potential of ORR process is considered as a "mixed potential" of two reactions (electrochemical reduction of surface atom ${ }_{\mathrm{s}, \mathrm{d}} \mathrm{Pt}^{\mathrm{II}}$ and consecutive oxidation of ${ }_{\mathrm{s}, \mathrm{d}} \mathrm{Pt}^{\mathrm{I}}$ by molecular oxygen), is substantiated. It is proposed that the formation of surface nanocluster transition state $\left[{ }^{*}(\mathrm{OO})_{s, \mathrm{~d}} \mathrm{Pt}^{\mathrm{s}}{ }^{\mathrm{I}}(\mathrm{OH})\right] \mathrm{defines}$ the rate of the entire ORR process on Pt-electrodes in alkaline media.
\end{abstract}

\section{Introduction}

Oxygen reduction reaction (ORR) is used in many electrochemical energy transformation devices (e.g., in lowtemperature fuel cells). ORR process is experimentally studied in detail and, as reflected in a number of classical reviews [1-4], there is an experimental determination that platinum and platinum based alloys are characterized by the highest electrochemical activity. Nevertheless, analysis of the ORR literature data indicates that oxygen Pt-electrodes have some characteristic features which still do not have a systematic explanation. For example, one can note the following experimental facts.

Fact \#1. In experimental conditions, the standard value of oxygen electrode potential $E=1.23 \mathrm{~V}$ in relation to the reversible hydrogen electrode (versus RHE) is not reproduced in either acidic (reaction (1)) or alkaline (reaction (2)) media:

$$
\begin{gathered}
\mathrm{O}_{2}+4 \mathrm{H}^{+}+4 \mathrm{e}^{-} \longleftrightarrow 2 \mathrm{H}_{2} \mathrm{O} \\
\mathrm{O}_{2}+2 \mathrm{H}_{2} \mathrm{O}+4 \mathrm{e}^{-} \longleftrightarrow 4 \mathrm{OH}^{-}
\end{gathered}
$$

As a rule, the stationary oxygen potential on polycrystalline [1-4] and monocrystalline [5-8] Pt-electrodes is reported within $0.9-1.1 \mathrm{~V}$ (versus $\mathrm{RHE}$ ) range.

Fact \#2. There is an observation of existence on polarization curves for Pt-electrodes [9] of the current interval $\left(10^{-7}-10^{-6} \mathrm{~A} \mathrm{sm}^{-2}\right)$ without an appreciative change of the potential.

Fact \#3. According to cyclic voltammogram (CVA) data, oxygen-containing surface structures (OSS) are formed on the surface of Pt-electrodes at the range of ORR potentials [5$8,10]$. There is a report [5] that these structures influence ORR process. Thus, in a solution of $\mathrm{HClO}_{4}(0.1 \mathrm{M})$, ORR process on $\mathrm{Pt}(111)$ monocrystal proceeds in accordance with reaction (1). An addition of $\mathrm{KBr}$ solution $\left(8 \cdot 10^{-4} \mathrm{M}\right)$ sharply changes the direction of ORR (the hydrogen peroxide $\mathrm{H}_{2} \mathrm{O}_{2}$ is formed instead of $\mathrm{H}_{2} \mathrm{O}$ molecule). The change of reaction direction correlates with change of state of monocrystal surface. Introduction of $\mathrm{Br}^{-}$ions leads to complete disappearance of peaks of formation of OSS on CVA (see Table 1). 
TABLE 1: Characteristics of CVA, potential of ORR start, $E_{\text {start }}$, ORR products on $\mathrm{Pt}(111)$ monocrystalline electrode [5].

\begin{tabular}{|c|c|c|c|c|c|}
\hline \multirow{2}{*}{ Electrolyte } & \multicolumn{4}{|c|}{ Potential, V (vs RHE) } & \multirow{2}{*}{ ORR product } \\
\hline & Interval of anodic current & Peak of anodic current & Peak of cathodic current & $E_{\text {start }}$ & \\
\hline $0.1 \mathrm{M} \mathrm{HClO}_{4}$ & $0.55-0.85$ & 0.75 & 0.75 & 0.90 & $\mathrm{H}_{2} \mathrm{O}$ \\
\hline $0.1 \mathrm{M} \mathrm{HClO}_{4}+10^{-4} \mathrm{M} \mathrm{KBr}$ & Absence of anodic current & Absence of anodic current & Absence of cathodic current & 0.65 & $\mathrm{H}_{2} \mathrm{O}_{2}$ \\
\hline
\end{tabular}

Fact \#4. In $1 \mathrm{M} \mathrm{H}_{2} \mathrm{SO}_{4}$ solution, ORR process on $\mathrm{Pt}(\mathrm{hkl})$ monocrystal electrodes proceeds in accordance with reaction (1) at $0.90-0.95 \mathrm{~V}$ (versus RHE). Addition of $0.1 \mathrm{M} \mathrm{HCl}$ solution sharply changes the potentials of start of ORR process down to $0.720-0.620 \mathrm{~V}$ (the potentials of $\mathrm{H}_{2} \mathrm{O}_{2}$ formation) [11].

Usage of concept of electrochemical process with slowed stage of consecutive heterogeneous chemical reaction (ConHCR) for systematic interpretation of characteristic parameters of ORR is substantiated in the author's publications $[12,13]$. In accordance with the concept, the ORR is described by Tafel equation with coefficient $b=\nu R T /(p \beta n F)$, where $\nu$ is the stoichiometric number (number of repetitions of the slow stage of heterogenous chemical reaction), $p$ is the reaction order with respect to oxygen, $n$ is the number of electrons involved in the electrochemical act before the slow stage, and $\beta$ is the parameter describing the energetic inhomogeneity of the electrode surface according to Temkin $(0<\beta<1)$. The $\beta=1$ parameter value corresponds to energetic homogeneity of the electrode surface. An analysis of the literature data resulted in the author's conclusion about dependence of parameter $\beta$ on type of $\mathrm{Pt}(\mathrm{hkl})$ monocrystals. It indicates energetic heterogeneousness of surface platinum atoms. In the publications cited above, the authors also proved a concept according to which the ORR process is realized with participation of surface binuclear oxygen (SBNO) nanoclusters on the base of OSS formed on the surface of Pt-electrodes in molecular oxygen atmosphere.

In the current work, analysis of energy characteristics of OSS (which serve as building blocks of SBNO nanoclusters) on surface of Pt-electrodes in alkaline medium is performed; these characteristics are compared with ORR process parameters. The analysis resulted in a new structure of SBNO nanoclusters and new multistage scheme of redox cycle of ORR with participation of SBNO nanoclusters.

\section{Comparison of ORR Characteristics with Parameters of Oxygen-Containing Structures on Surface of Pt-Electrodes}

2.1. Energy Characteristics of Electrochemical Reactions of Surface of Pt-Electrodes in Nitrogen Atmosphere (Alkaline Media). In studies $[14,15]$ by Appleby the "relative $\Delta G_{\text {ads }}(E)$ " parameter was used for energy characterization of adsorbed oxygencontaining - $\mathrm{OH}$ and/or -O particles on surface of metal electrodes. According to Appleby's concept, this parameter is a formal thermodynamic equivalent of the electrode potential. Analysis of dependence of current characteristics of oxygen electrodes on base of $\mathrm{Os}, \mathrm{Ru}, \mathrm{Rh}, \mathrm{Pd}, \mathrm{Pt}$, and $\mathrm{Au}$ in $85 \%$ solution of $\mathrm{H}_{3} \mathrm{PO}_{4}$ at $25^{\circ} \mathrm{C}$ was performed with utilization of "relative $\Delta G_{\text {ads }}\left(E^{\prime \prime}\right)$ " parameter [15]. Appleby used volts as a measurement unit; the parameter was linked to the potential at which, according to anodic cyclic voltammetry, formation of oxygen-containing particles is started.

Appleby's concept about possibility of utilization of potential of formation of surface oxygen-containing particles as the energy characteristic is used in the current work for analysis of surface electrochemical processes on Ptelectrodes. The parameter ${ }_{\mathrm{s}, \mathrm{d}} \Delta G^{*}$ is used as the energy characteristic. The parameter is formally defined as Gibbs energy of electrochemical process by the classical equation

$$
{ }_{\mathrm{s}, \mathrm{d}} \Delta G^{*}=-n F E,
$$

where $n$ is the number of electrochemical process electrons, $E$ is the potential, in relation to the standard hydrogen electrode (SHE), at which the electrochemical process takes place, and $F$ is the Faraday constant. The surface Pt atoms are also defects of the platinum crystal lattice; the energy characteristics of such atoms may differ from energy characteristics of crystal body's atoms; therefore, to highlight this, the subscripts $s$ and $d$ are used in the description of ${ }_{s, d} \Delta G^{*}$ parameter. The subscripts reflect terms "surface" and "defect" correspondingly.

The following equation was discussed in the review [4] as a probable electrochemical reaction on Pt-electrodes in acidic media in the absence of molecular oxygen:

$$
\mathrm{Pt}(\mathrm{OH})_{2}+2 \mathrm{H}^{+}+2 \mathrm{e}^{-} \longleftrightarrow \mathrm{Pt}+2 \mathrm{H}_{2} \mathrm{O} \text {. }
$$

The standard potential of this reaction is equal to $0.98 \mathrm{~V}$ (according to data from review [4] and handbook [16]). In alkaline solutions, reaction (4) should be rewritten as

$$
\begin{aligned}
\mathrm{Pt}(\mathrm{OH})_{2}+2 \mathrm{e}^{-} & \longleftrightarrow \mathrm{Pt}+2 \mathrm{OH}^{-} \\
\Delta G_{(298 \mathrm{~K})}^{0} & =-29 \mathrm{~kJ} \mathrm{~mol}^{-1},
\end{aligned}
$$

with the standard reaction potential equal to $0.15 \mathrm{~V}$ [16]. In (5), the standard value of Gibbs energy was calculated according to (3). Taking into account value of Gibbs energy $\Delta G^{0}{ }_{(298 \mathrm{~K})}\left(\mathrm{OH}^{-}\right)=-157.3 \mathrm{~kJ} \mathrm{~mol}^{-1}$ [3], the Gibbs energy of formation of $\mathrm{Pt}(\mathrm{OH})_{2}$ hydroxide was calculated on the basis of data in (5). The obtained value of Gibbs energy $\Delta G_{(298 \mathrm{~K})}^{0} \mathrm{Pt}(\mathrm{OH})_{2}=-285 \mathrm{~kJ} \mathrm{~mol}^{-1}$ is in agreement with the reference value of $-286 \mathrm{~kJ} \mathrm{~mol}^{-1}$ [17].

By taking into account the fact that surface Pt atoms are defects of crystal lattice [12], (5) may be presented in different format:

$$
{ }_{\mathrm{s}, \mathrm{d}} \mathrm{Pt}-2 \mathrm{e}^{-}+2 \mathrm{OH}^{-} \longleftrightarrow{ }_{\mathrm{s}, \mathrm{d}} \mathrm{Pt}(\mathrm{OH})_{2},
$$

where ${ }_{\mathrm{s}, \mathrm{d}} \mathrm{Pt}$ abbreviation denotes surface platinum atom which is, at the same time, a defect of the crystal lattice. Let us 
TABLE 2: Potentials of intervals of cyclic voltammograms and peaks potentials of anodic and cathodic currents at various temperatures on monocrystalline $[7,8]$ and polycrystalline $[3,10]$ Pt-electrodes.

\begin{tabular}{|c|c|c|c|c|c|c|}
\hline \multirow{3}{*}{ Electrode materials } & \multirow{3}{*}{ Temperature, $\mathrm{K}$} & \multicolumn{5}{|c|}{ Potentials*, V (vs RHE) } \\
\hline & & \multirow{2}{*}{ Interval } & \multicolumn{2}{|c|}{ Peak I } & \multicolumn{2}{|c|}{ Peak II } \\
\hline & & & anodic branch & cathodic branch & anodic branch & cathodic branch \\
\hline \multirow{2}{*}{$\operatorname{Pt}(111)$} & 293 & \multirow{2}{*}{$0.6-1.1$} & 0.78 & 0.78 & 1.05 & $1.00^{* *}$ \\
\hline & 333 & & 0.78 & 0.78 & 0.95 & 0.90 \\
\hline \multirow{2}{*}{$\operatorname{Pt}(110)$} & 293 & \multirow{2}{*}{$0.2-1.0$} & $0.30^{* *}$ & 0.45 & 0.75 & 0.65 \\
\hline & 333 & & 0.25 & 0.50 & 0.75 & 0.70 \\
\hline \multirow{2}{*}{$\operatorname{Pt}(100)$} & 293 & \multirow{2}{*}{$0.2-1.1$} & $0.60^{* *}$ & 0.60 & 1.00 & 0.95 \\
\hline & 333 & & 0.60 & 0.60 & 0.98 & 0.95 \\
\hline Pt smooth & 293 & $0.5-1.2$ & 0.7 & Absence of peak & 1.1 & 0.80 \\
\hline
\end{tabular}

${ }^{*}$ The values are approximate; they are results of author's processing of graphical data from publications $[3,7,8,10] ;{ }^{* *}$ Poorly defined peak; ${ }^{* * *}$ There are significant currents between peaks I and II on cyclic voltammograms' anodic branches for $\mathrm{Pt}(110)$ and $\mathrm{Pt}(100)$ monocrystalline and polycrystalline $\mathrm{Pt}$-electrodes.

note that reaction (6), contrary to reaction (5), is written in anodic format. Therefore, for this reaction, the Gibbs energy is designated with ${ }_{\mathrm{s}, \mathrm{d}} \Delta G_{a}{ }^{*}$ symbol, where subscript $a$ indicates anodic process. Calculation of the parameter is carried out according to (3) on condition that ${ }_{\mathrm{s}, \mathrm{d}} \Delta G_{a}{ }^{*}=-{ }_{\mathrm{s}, \mathrm{d}} \Delta G^{*}$.

Reaction (6), in principle, may occur in two stages. In first stage, oxygen-containing ${ }_{s, d} \mathrm{Pt}^{\mathrm{I}}(\mathrm{OH})$ structure would be formed:

$$
{ }_{\mathrm{s}, \mathrm{d}} \mathrm{Pt}-\mathrm{e}^{-}+\mathrm{OH}^{-} \longleftrightarrow{ }_{\mathrm{s}, \mathrm{d}} \mathrm{Pt}^{\mathrm{I}}(\mathrm{OH})
$$

In the second stage, ${ }_{\mathrm{s}, \mathrm{d}} \mathrm{Pt}^{\mathrm{II}}(\mathrm{OH})_{2}$ structure will be formed:

$$
{ }_{\mathrm{s}, \mathrm{d}} \mathrm{Pt}^{\mathrm{I}}(\mathrm{OH})-\mathrm{e}^{-}+\mathrm{OH}^{-} \longleftrightarrow{ }_{\mathrm{s}, \mathrm{d}} \mathrm{Pt}^{\mathrm{II}}(\mathrm{OH})_{2} \text {. }
$$

Symbols "I" and "II" reflect valence state of ${ }_{\mathrm{s}, \mathrm{d}} \mathrm{Pt}$ atom as there is a difficulty in interpretation of the value of positive charge of the surface atom. In the authors' opinion, the twostage variant of the process finds reflection on anodic and cathodic CVA branches. The results of analysis of literature data on monocrystalline and polycrystalline Pt-electrodes are presented in Table 2.

Table 2 data indicates that two peaks of anodic current appear on anodic branches of cyclograms only for $\mathrm{Pt}(111)$ monocrystals and polycrystalline Pt-electrodes. Let us note that the second peak of anodic current on monocrystalline $[7,8]$ and polycrystalline $[3,10]$ Pt-electrodes takes place within the $1.0-1.1 \mathrm{~V}$ (versus RHE) region of stationary ORR potentials. On monocrystals $\mathrm{Pt}(110)$ and $\mathrm{Pt}(100)$, only the second anodic current peak is clearly seen. The first peak on these monocrystals is poorly defined. Reversibility of the processes for both anodic current peaks on cathodic branches of CVA is most pronounced at elevated temperatures [7, 8]. On $\mathrm{Pt}(110)$ and $\mathrm{Pt}(100)$ monocrystals, reversibility is observed at all tested temperatures $[7,8]$. On cathodic branches of cyclograms for polycrystalline Pt-electrodes reversibility is absent for both peaks of anodic current [3, 10]. On the other hand, one may interpret the potential of cathodic peak at $0.8 \mathrm{~V}$ (versus RHE) as a summary of potentials of huge number of various monocrystals $\mathrm{Pt}(\mathrm{hkl})$ which are presented on the surface of polycrystalline platinum as a complicated mosaic. Indeed, according to Table 2 data medium sum of potentials of peaks II on cathodic branches CVA for $\mathrm{Pt}(111)$, $\mathrm{Pt}(110)$, and $\mathrm{Pt}(100)$ monocrystals is equal to $0.87 \mathrm{~V}$ (versus $\mathrm{RHE})$ at $293 \mathrm{~K}$ temperature.

During analysis of CVAs, one should take into account the character of location of ${ }_{\mathrm{s}, \mathrm{d}} \mathrm{Pt}$ atoms on $\mathrm{Pt}(\mathrm{hlk})$ monocrystals surface; differences in CVA characters are, in author's opinion, consequences of various locations of ${ }_{s, d} \mathrm{Pt}$ atoms on surface of $\mathrm{Pt}(\mathrm{hkl})$ monocrystals. In principle, by taking into account radius of $\mathrm{Pt}$ atoms $(139 \mathrm{pm})$ and lattice parameter $(392 \mathrm{pm})$ the character of density of atoms packing may be reflected with ${ }_{\mathrm{s}, \mathrm{d}} \mathrm{N}_{\mathrm{Pt}}$ parameter (quantity of ${ }_{\mathrm{s}, \mathrm{d}} \mathrm{Pt}$ atoms on $1 \mathrm{~nm}^{2}$ ). The most dense packing of ${ }_{\mathrm{s}, \mathrm{d}} \mathrm{Pt}$ atoms is the characteristic of $\mathrm{Pt}(111)$ monocrystals. For such packing each surface atom is surrounded by 6 other atoms on interatomic distance of 278 pm (see Figure 1).

Monocrystals $\mathrm{Pt}(110)$ are characterized by the least dense surface atoms ${ }_{\mathrm{s}, \mathrm{d}} \mathrm{Pt}\left({ }_{\mathrm{s}, \mathrm{d}} \mathrm{N}_{\mathrm{Pt}}=9\right)$ packing. Two peculiarities of atoms distribution take place in this case. First, each atom has a close contact with only 2 other surface atoms (on interatomic distance of $278 \mathrm{pm}$ ). Second, electrolyte components obtain access to subsurface atoms of Pt crystal due to large interatomic distance $(392 \mathrm{pm})$ between "remote neighbors" ${ }_{s, d} \mathrm{Pt}$ atoms in the surface layer. Monocrystals $\mathrm{Pt}(100)$ are characterized by medium density of surface atoms ${ }_{\mathrm{s}, \mathrm{d}} \mathrm{Pt}$ $\left({ }_{s, d} \mathrm{~N}_{\mathrm{Pt}}=13\right)$ packing. For this packing there are following peculiarities of atoms distribution. First, each surface atom has only 4 neighbor ${ }_{s, d} \mathrm{Pt}$ atoms on interatomic distance of $278 \mathrm{pm}$. Second, for the medium dense packing electrolyte components also have access into subsurface platinum atoms due to large interatomic distance $(392 \mathrm{pm})$ between "remote neighbors" s,d Pt atoms.

Due to monolithicity of surface layer of platinum atoms on $\mathrm{Pt}(111)$ monocrystal the proceeding of reactions (7) and (8) is expressed on CVA as two well defined anodic peaks within a fairly narrow interval of potentials (see Table 2). One may assume that peak I with anodic CVA branch maximum at $0.78 \mathrm{~V}$ (versus RHE) (which could be recalculated as $-0.05 \mathrm{~V}$ (versus SHE)) corresponds to proceeding of reaction (7). Therefore, peak II with anodic CVA branch maximum at $1.05 \mathrm{~V}$ (versus RHE) (recalculated as $0.22 \mathrm{~V}$ (versus SHE)) 


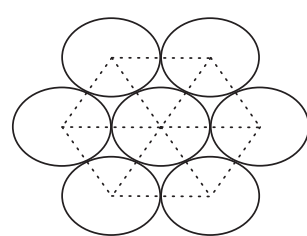

$\operatorname{Pt}(111)$

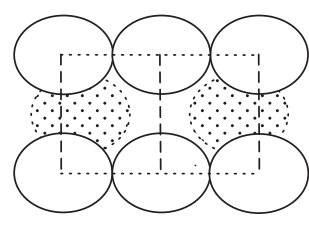

$\operatorname{Pt}(110)$

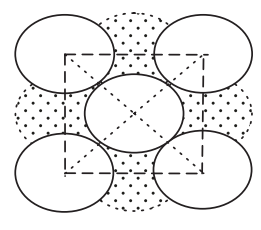

$\operatorname{Pt}(100)$

atom of undersurface layer

..... interatomic distance of $278 \mathrm{pm}$

-- $\quad$ interatomic distance of $392 \mathrm{pm}$

Figure 1: Scheme of atoms' locations on the surface of Pt(hkl) monocrystals.

corresponds to proceeding of reaction (8). According to (3) values of ${ }_{\mathrm{s}, \mathrm{d}} \Delta G_{a}{ }^{*}$, parameter calculated for -0.05 and $0.22 \mathrm{~V}$ (versus SHE) potentials is equal to -5 and $21 \mathrm{~kJ} \mathrm{~mol}^{-1}$, correspondingly. Let us note that the subscript symbol $a$ in description of ${ }_{\mathrm{s}, \mathrm{d}} \Delta G_{a}{ }^{*}$ parameter reflects correspondence of reactions (7) and (8) to anodic process. Following the described above method the values of ${ }_{\mathrm{s}, \mathrm{d}} \Delta G_{a}{ }^{*}$ parameter were calculated for other Pt-electrode types (see Table 3).

Analysis of Table 3 data leads to the following conclusions.

(1) The surface oxygen-containing structure ${ }_{s, d} \mathrm{Pt}^{\mathrm{I}} \mathrm{OH}$ in alkaline media and absence of molecular oxygen could be considered as a stable formation on all Pt-electrode types (as for reaction (7) $\left.{ }_{\mathrm{s}, \mathrm{d}} \Delta G_{a}{ }^{*}<0\right)$.

(2) The surface oxygen-containing structure ${ }_{s, d} \mathrm{Pt}^{\mathrm{II}}(\mathrm{OH})_{2}$ in alkaline media is not stable formations on smooth metal, $\mathrm{Pt}$ (111) and Pt(100) monocrystal Pt-electrodes. These structures decompose down to ${ }_{\mathrm{s}, \mathrm{d}} \mathrm{Pt}^{\mathrm{I}} \mathrm{OH}$ as for reaction (8) ${ }_{\mathrm{s}, \mathrm{d}} \Delta G_{a}{ }^{*}>$ 0 .

Parameters ${ }_{\mathrm{s}, \mathrm{d}} \Delta G_{a}{ }^{*}$ and ${ }_{\mathrm{s}, \mathrm{d}} \Delta G_{k}{ }^{*}$ of formation of oxygencontaining structures ${ }_{\mathrm{s}, \mathrm{d}} \mathrm{Pt}^{\mathrm{II}}(\mathrm{OH})_{2}$ and ${ }_{\mathrm{sd}} \mathrm{Pt}^{\mathrm{I}} \mathrm{OH}$ were calculated from Table 3 data. The parameters were determined for monocrystalline $\mathrm{Pt}(\mathrm{hkl})$ and polycrystalline Pt-electrodes (see Table 4). Note that the subscript symbol $k$ in description of ${ }_{\mathrm{s}, \mathrm{d}} \Delta G_{k}{ }^{*}$ parameter reflects correspondence of reactions (7) and (8) to cathodic process. The calculations were performed for maximums of peaks on anodic and cathodic CVA branches (see Table 2). Only single wide peak is observed on cathodic CVA branch (see Table 2) for smooth platinum electrodes. Such peak could be interpreted as summing result of multiple surface $\mathrm{Pt}(\mathrm{hkl})$ monocrystals. Therefore, for smooth platinum the parameter ${ }_{\mathrm{s}, \mathrm{d}} \Delta G_{k}{ }^{*}$ is calculated as $1 / 3$ of sum of parameter values for $\mathrm{Pt}(111), \mathrm{Pt}(110)$, and $\mathrm{Pt}(100)$ monocrystals.

Analysis of Table 4 data leads to the following conclusions.

(1) A correlation between values of ${ }_{\mathrm{s}, \mathrm{d}} \Delta G_{a}{ }^{*}$ and ${ }_{\mathrm{s}, \mathrm{d}} \mathrm{N}_{\mathrm{Pt}}$ parameters is detected. For all surface oxygen-containing structures decrease of density of surface atoms packing correlates with increase of parameter ${ }_{\mathrm{s}, \mathrm{d}} \Delta G_{a}{ }^{*}$ absolute value. For oxygen-containing structure ${ }_{s, d} \mathrm{Pt}^{\mathrm{II}}(\mathrm{OH})_{2}$ the decrease of parameter ${ }_{\mathrm{s}, \mathrm{d}} \mathrm{N}_{\mathrm{Pt}}$ values in 17, 13, 9 atoms row corresponds to increase of absolute values of parameter ${ }_{\mathrm{s}, \mathrm{d}} \Delta G_{a}{ }^{*}$ in -298 ,
-320 , and $-373 \mathrm{~kJ} \mathrm{~mol}^{-1}$ row. For oxygen-containing structure ${ }_{\mathrm{s}, \mathrm{d}} \mathrm{Pt}^{\mathrm{I}}(\mathrm{OH})$ the decrease of parameter ${ }_{\mathrm{s}, \mathrm{d}} \mathrm{N}_{\mathrm{Pt}}$ values in the same atoms row corresponds to increase of absolute values of parameter ${ }_{\mathrm{s}, \mathrm{d}} \Delta G_{a}{ }^{*}$ in $-162,-179$, and $-208 \mathrm{~kJ} \mathrm{~mol}^{-1}$ row.

(2) Parameter ${ }_{\mathrm{s}, \mathrm{d}} \Delta G_{a}{ }^{*}$ values for oxygen-containing structures on smooth and $\mathrm{Pt}$ (111) Pt-electrodes are close to each other $\left(300\right.$ and $298 \mathrm{~kJ} \mathrm{~mol}^{-1}$ for ${ }_{\mathrm{s}, \mathrm{d}} \mathrm{Pt}^{\mathrm{I}}(\mathrm{OH})$ and 169 and $162 \mathrm{~kJ} \mathrm{~mol}^{-1}$ for ${ }_{\mathrm{s}, \mathrm{d}} \mathrm{Pt}^{\mathrm{II}}(\mathrm{OH})_{2}$, correspondingly). The closeness of parameter ${ }_{\mathrm{s}, \mathrm{d}} \Delta G_{a}{ }^{*}$ values means that the energy properties of polycrystalline platinum in the anodic process correspond to the most dense packing of surface atoms on Pt(111) monocrystals.

(3) Nearly identical values of parameters ${ }_{s, d} \Delta G_{a}{ }^{*}$ and ${ }_{\mathrm{s}, \mathrm{d}} \Delta G_{k}{ }^{*}$ for cases of $\mathrm{Pt}(111)$ and $\mathrm{Pt}(100)$ monocrystals reflect reversibility of reaction (7) and, correspondingly, the equality of potentials of peaks I on anodic and cathodic CVA branches (see Table 2).

(4) The parameters ${ }_{\mathrm{s}, \mathrm{d}} \Delta G_{a}{ }^{*}$ presented in Table 4 shall be considered as data for surface oxygen-containing structures which were obtained in specific experimental conditions. It is caused by a fact that values of ${ }_{\mathrm{s}, \mathrm{d}} \Delta G_{a}{ }^{*}$ parameters are directly connected with values of anodic peak on CVA. Note that values of ${ }_{\mathrm{s}, \mathrm{d}} \Delta G_{a}{ }^{*}$ parameter correspond to potentials of anodic peaks on smooth Pt-electrodes at 0.7 and $1.1 \mathrm{~V}$ (see Table 2). However, in study [18] during investigation of CVA on smooth Pt-electrodes in $\mathrm{KOH}$ solutions with various concentrations (from 0.1 to $6.9 \mathrm{M}$ ) a weak appearance of two anodic peaks on CVA was observed at different potentials. First peak the authors connected with platinum oxidation up to $\mathrm{PtOH}$ structure. The potential of this peak fluctuated within 0.840 to $0.820 \mathrm{~V}$ (versus $\mathrm{RHE}$ ) range. The second peak the authors associated with formation of $\mathrm{Pt}(\mathrm{OH})_{2}$ structure. The potential of the second peak fluctuated within 0.96 to $1.00 \mathrm{~V}$ (versus RHE) interval.

The values of parameter ${ }_{\mathrm{s}, \mathrm{d}} \Delta G^{*}$ presented in Table 4 are directly related to potentials of anodic peaks I and II from Table 2. Let us note that the character of dependence of anodic current on potential within the range of potentials between the peaks I and II depends on type of Pt(hkl) monocrystals and surface packing density of platinum atoms $\left({ }_{s, d} R\right.$ parameter) [13]. In a case of the most dense packing of ${ }_{\mathrm{s}, \mathrm{d}} \mathrm{Pt}$ atoms corresponding to the $\mathrm{Pt}(111)$ monocrystals, a 
TABLE 3: Potentials of CVA anodic peaks and ${ }_{s, \mathrm{~d}} \Delta G_{a}{ }^{*}$ parameter of electrochemical reactions (7) and (8) on Pt-electrodes.

\begin{tabular}{|c|c|c|c|c|}
\hline \multirow{2}{*}{ Electrode materials } & \multicolumn{2}{|c|}{ Potential, V (vs SHE) } & \multicolumn{2}{|c|}{${ }_{\mathrm{s}, \mathrm{d}} \Delta G_{a}{ }^{*}, \mathrm{~kJ} \cdot \mathrm{mol}^{-1}$} \\
\hline & Peak I & Peak II & Reaction (7) & Reaction (8) \\
\hline $\operatorname{Pt}(111)$ & -0.05 & 0.22 & -5 & 21 \\
\hline $\operatorname{Pt}(110)$ & -0.53 & -0.08 & -51 & -8 \\
\hline $\operatorname{Pt}(100)$ & -0.23 & 0.17 & -22 & 16 \\
\hline Pt smooth & -0.13 & 0.27 & -12 & 26 \\
\hline
\end{tabular}

TABle 4: Parameter ${ }_{s, d} \Delta G^{*}$ for oxygen-containing structures on the surface of Pt-electrodes in nitrogen atmosphere.

\begin{tabular}{|c|c|c|c|c|c|c|c|c|}
\hline \multirow{3}{*}{ Structure } & \multicolumn{8}{|c|}{${ }_{\mathrm{s}, \mathrm{d}} \Delta G^{*}, \mathrm{~kJ} \cdot \mathrm{mol}^{-1}$} \\
\hline & \multicolumn{2}{|c|}{$\begin{array}{c}\mathrm{Pt}(111) \\
\left({ }_{s, \mathrm{~d}} \mathrm{~N}_{\mathrm{Pt}}=17\right)\end{array}$} & \multicolumn{2}{|c|}{$\begin{array}{c}\mathrm{Pt}(100) \\
\left({ }_{s, \mathrm{~d}} \mathrm{~N}_{\mathrm{Pt}}=13\right)\end{array}$} & \multicolumn{2}{|c|}{$\begin{array}{c}\operatorname{Pt}(110) \\
\left(\begin{array}{c}\left.{ }_{s, d} N_{P t}=9\right)\end{array}\right.\end{array}$} & \multicolumn{2}{|c|}{ Pt smooth } \\
\hline & $\mathrm{s, \textrm {d }} \Delta G_{a}{ }^{*}$ & $\mathrm{s, \textrm {d }} \Delta G_{k}{ }^{*}$ & ${ }_{\mathrm{s}, \mathrm{d}} \Delta G_{a}{ }^{*}$ & $\mathrm{s, \textrm {d }} \Delta G_{k}{ }^{*}$ & $\mathrm{s, \textrm {d }} \Delta G_{a}{ }^{*}$ & ${ }_{\mathrm{s}, \mathrm{d}} \Delta G_{k}{ }^{*}$ & $\mathrm{s, \textrm {d }} \Delta G_{a}{ }^{*}$ & $\mathrm{s, \textrm {d }} \Delta G_{k}{ }^{*}$ \\
\hline${ }_{s, \mathrm{~d}} \mathrm{Pt}^{\mathrm{I}} \mathrm{OH}$ calculation according to reaction (7) & -162 & -162 & -179 & -179 & -208 & -194 & -169 & $(-178)^{*}$ \\
\hline${ }_{s, \mathrm{~d}} \mathrm{Pt}^{\mathrm{II}}(\mathrm{OH})_{2}$ Calculation according to reaction (8) & -298 & -303 & -320 & -324 & -373 & -300 & -300 & $(-309)^{*}$ \\
\hline
\end{tabular}

${ }^{*}$ averaged value of ${ }_{s, \mathrm{~d}} \Delta G_{k}{ }^{*}$ parameters on $\mathrm{Pt}(\mathrm{hkl})$ monocrystals.

sharp decrease of anodic current (between the peaks I and II) is observed up to the middle of the range of potentials between peaks I and II $[7,8]$. It follows with a sharp increase of the anodic current. The observed character of dependence of anodic current on potential on $\mathrm{Pt}(111)$ monocrystals proves simultaneous participation of all ${ }_{\mathrm{s}, \mathrm{d}} \mathrm{Pt}$ atoms in reaction (7), and later in reaction (8). It indicates energetic homogeneity of electrode surface according to Temkin on Pt(111) monocrystals. Correspondingly the parameter $\beta$ in the Tafel equation is close to 1 [13].

In a case of $\mathrm{Pt}(110), \operatorname{Pt}(100)$ monocrystals, and polycrystalline Pt-electrodes the range of potentials between weak peaks I and II is characterized by practically the same values of the anodic current (without clearly defined minimum of the current) $[7,8,10]$. The observed character of dependence of anodic current on potential on $\mathrm{Pt}(110)$ and $\mathrm{Pt}(100)$ monocrystals indicates that the atoms with various energetic characteristics participate in reactions (7) and (8). For example, the platinum atoms from the surface and subsurface layers take part in the above reactions (see Figure 1). It indicates an existence of energetic inhomogeneity of electrode surface according to Temkin on such monocrystals. Correspondingly, the parameter $\beta$ in the Tafel equation is significantly smaller than 1 [13].

The surface of polycrystalline Pt-electrode is a complex combination of $\mathrm{Pt}(\mathrm{hkl})$ monocrystals. Therefore, the energetic properties of surface of all $\mathrm{Pt}(\mathrm{hkl})$ monocrystals shall contribute to ORR process. The analysis of literature data indicated that value of parameter $\beta$ depends on intensity of ORR process. In the range of low values of anodic current, the parameter $\beta$ is equal to 1 ; it corresponds to energetic homogeneity of electrode surface according to Temkin. In the range of high values of anodic current, the parameter $\beta$ is sharply decreased down to $0.3-0.5$ range; it corresponds to energetic inhomogeneity of electrode surface according to Temkin. Therefore, one may assume that at low current values the ORR process is primarily realized via participation of surface atoms of $\mathrm{Pt}(111)$ monocrystals. Correspondingly at high current values, the surface atoms from $\mathrm{Pt}(110)$ and $\mathrm{Pt}(100)$ monocrystals get involved in the ORR process.

The presented conclusions are alternative to the concepts currently used in the literature for interpretation of electrochemical processes on platinum electrodes in inert atmosphere. For example, in studies $[19,20]$ for analysis of "electrosorption" processes a formation of surface structures $\mathrm{Pt}_{3} / \mathrm{OH}$ and $\mathrm{Pt}_{3} /(\mathrm{OH})_{2}$ is proposed on $\mathrm{Pt}(111)$ monocrystals and formation of $\mathrm{Pt}_{4} / \mathrm{OH}, \mathrm{Pt}_{2} / \mathrm{OH}, \mathrm{Pt} / \mathrm{OH}$ structures is proposed on $\mathrm{Pt}(100)$ monocrystals. The $\mathrm{Pt}_{x} / \mathrm{OH}$ structures, in opinion of the studies' authors, are not stoichiometric formations. The structures only reflect ratio of neutral $\mathrm{Pt}$ atoms and $\mathrm{OH}$ particulates on the surface of platinum electrode. Particles $\mathrm{OH}$ are formed, according to the studies' authors, as a result of proton and electron loss by water molecule at high positive potentials (reaction $\mathrm{Pt}+\mathrm{H}_{2} \mathrm{O} \leftrightarrow \mathrm{Pt} / \mathrm{OH}+\mathrm{H}^{+}+\mathrm{e}^{-}$). But there is very low probability that hypothesis of formation of $\mathrm{OH}$ radical at potentials $0.9-1.0 \mathrm{~V}$ (versus RHE) is correct one. The fact is that the standard potential of reaction $\mathrm{OH}_{(\mathrm{r})}+$ $\mathrm{e}^{-} \leftrightarrow \mathrm{OH}^{-}$is equal to $2.02 \mathrm{~V}$ [16] (which is equivalent to $2.85 \mathrm{~V}$ (versus RHE)). Therefore, interpretation of electrochemical processes in absence of molecular oxygen as "electrosorption" of $\mathrm{OH}$ radicals on polycrystalline $\mathrm{Pt}$-electrodes is seen as one which does not correspond to the real processes.

In studies [2,3] oxygen-containing particles, formed as a result of electrochemical processes on Pt-electrodes in absence of molecular oxygen, are interpreted as "chemisorbed oxygen". Schemes which were proposed in study [2] for a case of Pt-electrodes in alkaline media have a simple format: $\mathrm{Pt}+\mathrm{OH}^{-} \leftrightarrow \mathrm{PtOH}+\mathrm{e}^{-}$. Unfortunately, in the above studies attention is not accented on nature of oxygen particle "OH" and on energy state of Pt atoms. Therefore, in the above interpretation it is still unclear whether discharge of $\mathrm{OH}^{-}$ happens with formation of $\mathrm{OH}$ radical or electrochemical oxidation of surface $\mathrm{Pt}$ atom takes place. In the current article a small probability of formation of $\mathrm{OH}$ radical was already 
TABle 5: Parameter ${ }_{s, \mathrm{~d}} \Delta G_{a}{ }^{*}$ for chemical reactions (10)-(12) on Pt-electrodes.

\begin{tabular}{lccc}
\hline Electrode material & & $\mathrm{s}, \mathrm{d} \Delta G_{a}{ }^{*}, \mathrm{~kJ} \cdot \mathrm{mol}^{-1}$ & reaction $(12)$ \\
reaction $(11)$ & -17 & -61 \\
$\operatorname{Pt}(111)$ & reaction $(10)$ & -46 & -136 \\
$\operatorname{Pt}(110)$ & -44 & -23 & -83 \\
$\operatorname{Pt}(100)$ & -90 & -12 & -63 \\
$\operatorname{Pt}$ smooth & -60 & -51 & \\
\hline
\end{tabular}

mentioned. The author considered formation of surface oxygen-containing structure ${ }_{\mathrm{s}, \mathrm{d}} \mathrm{Pt}^{\mathrm{I}}(\mathrm{OH})$ according to reaction (7) as the most probable pathway explaining electrochemical processes on Pt-electrodes in absence of molecular oxygen.

\subsection{Energy Characteristics of Electrochemical Reactions of} Surface of Pt-Electrodes in Molecular Oxygen Atmosphere (Alkaline Media). Estimations of energy parameters of reaction,

$$
\begin{aligned}
\mathrm{Pt}+0.5 \mathrm{O}_{2}+\mathrm{H}_{2} \mathrm{O} & \longleftrightarrow \mathrm{Pt}(\mathrm{OH})_{2}, \\
\Delta G_{(298 \mathrm{~K})}^{0} & =-48 \mathrm{~kJ} \mathrm{~mol}^{-1},
\end{aligned}
$$

indicate that chemical oxidation of smooth platinum is highly probable in $\mathrm{KOH}$ solutions in molecular oxygen atmosphere. For calculation of $\Delta G^{0}{ }_{(298 \mathrm{~K})}$ parameter the values $\Delta G^{0}{ }_{(298 \mathrm{~K})}\left(\mathrm{H}_{2} \mathrm{O}\right)=-237.2 \mathrm{~kJ} \mathrm{~mol}^{-1}$ [3] and $\Delta G^{0}{ }_{(298 \mathrm{~K})}$ $\left(\mathrm{Pt}(\mathrm{OH})_{2}\right)=-285 \mathrm{~kJ} \mathrm{~mol}^{-1}$ were used (see (5) related calculations). Correspondingly, oxidation of surface of $\mathrm{Pt}(\mathrm{hkl})$ monocrystals and polycrystalline Pt is also a highly probable pathway. The following reactions may proceed in the presence of molecular oxygen on surface of $\mathrm{Pt}(\mathrm{hkl})$ monocrystals and smooth Pt in KON solutions:

$$
\begin{aligned}
\text { s,d } \mathrm{Pt}+0.25 \mathrm{O}_{2}+0.5 \mathrm{H}_{2} \mathrm{O} & \longleftrightarrow{ }_{\mathrm{s}, \mathrm{d}} \mathrm{Pt}^{\mathrm{I}}(\mathrm{OH}), \\
{ }_{\mathrm{s}, \mathrm{d}} \mathrm{Pt}^{\mathrm{I}}(\mathrm{OH})+0.25 \mathrm{O}_{2}+0.5 \mathrm{H}_{2} \mathrm{O} & \longleftrightarrow{ }_{\mathrm{s}, \mathrm{d}} \mathrm{Pt}^{\mathrm{II}}(\mathrm{OH})_{2}, \\
{ }_{\mathrm{s}, \mathrm{d}} \mathrm{Pt}+0.5 \mathrm{O}_{2}+\mathrm{H}_{2} \mathrm{O} & \longleftrightarrow{ }_{\mathrm{s}, \mathrm{d}} \mathrm{Pt}^{\mathrm{II}}(\mathrm{OH})_{2} .
\end{aligned}
$$

To calculate values of ${ }_{\mathrm{s}, \mathrm{d}} \Delta G_{a}{ }^{*}$ parameter for reactions (10)-(12) the values of ${ }_{\mathrm{s}, \mathrm{d}} \Delta G_{a}{ }^{*}$ parameter for corresponding oxygen-containing structures from Table 4 were used. The results of such calculations are presented in Table 5 .

Analysis of Table 5 data leads to the following conclusions.

(1) Molecular oxygen in $\mathrm{KOH}$ solutions is able to oxidize atoms of smooth $\mathrm{Pt}$ (for reaction (9) $\Delta G^{0}{ }_{(298 \mathrm{~K})}<0$ ) and defects of crystal lattice ${ }_{\mathrm{s}, \mathrm{d}} \mathrm{Pt}$ (for reactions (10), (11), and (12) $\left.{ }_{\mathrm{s}, \mathrm{d}} \Delta G_{a}{ }^{*}<0\right)$.

(2) The ${ }_{s, d} \mathrm{Pt}^{\mathrm{I}}(\mathrm{OH})$ structure may be oxidized by molecular oxygen as for reaction (11) the value of parameter ${ }_{\mathrm{s}, \mathrm{d}} \Delta G_{a}{ }^{*}$ is less than zero $\left({ }_{\mathrm{s}, \mathrm{d}} \Delta G_{a}{ }^{*}<0\right)$ on all types of Pt-electrodes.

(3) In the presence of molecular oxygen ${ }_{\mathrm{s}, \mathrm{d}} \mathrm{Pt}^{\mathrm{II}}(\mathrm{OH})_{2}$ structure becomes a stable formation as for reaction (12) ${ }_{\mathrm{s}, \mathrm{d}} \Delta G_{a}{ }^{*}<0$ on all types of Pt-electrodes.

(4) Energy properties of smooth Pt are the most close to those of $\mathrm{Pt}(111)$ monocrystals. For example, for reaction
(12) values of parameter ${ }_{\mathrm{s}, \mathrm{d}} \Delta G_{a}{ }^{*}$ are equal to -63 and $-61 \mathrm{~kJ}$ $\mathrm{mol}^{-1}$, correspondingly.

(5) Parameter ${ }_{\mathrm{s}, \mathrm{d}} \Delta G_{a}{ }^{*}$ for formation of surface oxygencontaining ${ }_{s, d} \mathrm{Pt}^{\mathrm{II}}(\mathrm{OH})_{2}$ structure on smooth $\mathrm{Pt}$ in the result of chemical reaction (12) has higher absolute value than $\Delta G^{0}{ }_{(298 \mathrm{~K})}$ value of formation of hydroxide $\mathrm{Pt}(\mathrm{OH})_{2}$ in the result of reaction (9) (-63 and $-48 \mathrm{~kJ} \mathrm{~mol}^{-1}$, correspondingly).

2.3. Comparison of ORR Characteristics in Alkaline Media with Parameters of Oxygen-Containing Formations on PtElectrodes. Consecutive realization of cathodic variant of reactions (8) and (11) is a core of the concept of ORR process with slowed stage of ConGHR with participation of SBNO nanoclusters $[12,13]$. Binuclear nanoclusters model is based on a concept of proceeding of ORR process with participation of two Pt atoms ("bridge model" [21]). Let us note that binuclear model was used in theoretical study [22]. Surface binuclear oxygen structure from two neutral Pt atoms Pt-$\mathrm{O}_{2}$--Pt was a basis of that study. In the study a model based on multinuclear cluster $\mathrm{Pt}_{5} \mathrm{O}_{2}$ (ads) was also utilized.

Reaction (11) factually unites two electrochemical systems: cathodic reaction (2) and anodic reaction (8). Potential of cathodic reaction (2) in $\mathrm{KOH}$ solution is equal to $1.23 \mathrm{~V}$ (versus RHE). Anodic potential, $E_{a(8)}$, of reaction (8) corresponds to potentials of anodic peaks II (see Table 2). As a result, the averaged potential, $E_{\text {mix }}$, at which reaction (11)) may proceed is established. Similar methods of calculation of parameter $E_{\text {mix }}$ ("mixed potential") were used in studies $[23,24]$ for investigation of stationary potentials on Ptelectrodes in $2 \mathrm{~N} \mathrm{H}_{2} \mathrm{SO}_{4}$. The studies' author assumed that platinum surface is not inert in relation to molecular oxygen and that reaction $\mathrm{Pt}-\mathrm{O}+2 \mathrm{H}^{+}+2 \mathrm{e}^{-} \leftrightarrow \mathrm{Pt}+\mathrm{H}_{2} \mathrm{O}$ is realized in acidic solutions. The standard potential of this reaction is equal to $0.90 \mathrm{~V}$ [16]. Therefore, a "mixed potential" with some intermediate value in the 0.9 to $1.23 \mathrm{~V}$ range should be observed on Pt-electrodes. The stationary potential with values within narrow $1.17-1.16 \mathrm{~V}$ (versus RHE) interval was observed in experimental studies [23, 24]; it was explained by the studies' author as manifestation of the "mixed potential". Let us note that potential of cathodic reaction (2) remains practically unchanged value in a course of reaction (11) in the oxygen atmosphere. The potential of anodic reaction (8) which factually defines the potential of platinum electrode depends on level of oxidation of platinum electrode surface. In the ideal case when whole surface of platinum electrode is covered by the oxygen-containing ${ }_{\mathrm{s}, \mathrm{d}} \mathrm{Pt}^{\mathrm{II}}(\mathrm{OH})_{2}$ structures the potential of platinum electrode may reach 
TABLE 6: Potential of ORR start, $E_{\text {start }}$, and activation polarization, $\eta_{\text {mix }}$, for monocrystalline (in $\mathrm{KOH}$ solution $[7,8]$ ) and smooth (in $\mathrm{KOH}$ and $\mathrm{H}_{2} \mathrm{SO}_{4}$ solutions [2]) Pt-electrodes.

\begin{tabular}{lcc}
\hline Electrode materials & Potential $E_{\text {start }}, \mathrm{V}$ (vs RHE) & Polarization $\eta_{\text {mix }}, \mathrm{V}$ \\
\hline $\operatorname{Pt}(111)\left({ }_{s, d} \mathrm{~N}_{\mathrm{Pt}}=17\right)$ & 1.05 & -0.18 \\
$\operatorname{Pt}(100)\left({ }_{s, \mathrm{~d}} \mathrm{~N}_{\mathrm{Pt}}=13\right)$ & 0.95 & -0.28 \\
$\operatorname{Pt}(110)\left({ }_{s, \mathrm{~d}} \mathrm{~N}_{\mathrm{Pt}}=9\right)$ & 0.9 & -0.33 \\
$\operatorname{Pt}$ smooth $(\mathrm{KOH})$ & 1.1 & -0.13 \\
$\operatorname{Pt}$ smooth $\left(\mathrm{H}_{2} \mathrm{SO}_{4}\right)$ & 1.05 & -0.18 \\
\hline
\end{tabular}

$1.23 \mathrm{~V}$ value. But in real experiments, presence of various impurities in the electrolyte which have an ability to reduce the oxygen-containing ${ }_{s, d} \mathrm{Pt}^{\mathrm{II}}(\mathrm{OH})_{2}$ structures does not allow the electrode potential to reach $1.23 \mathrm{~V}$ value [4]. Effect of achievement of $1.23 \mathrm{~V}$ potential on Pt-electrode is reported in study [25]. The effect was achieved due to preliminary electrolyte purification via 60 -hour anodic electrolysis. But within several hours the $1.23 \mathrm{~V}$ potential gradually decreased to $1.1 \mathrm{~V}$ value. In experiments with alkaline electrolytes without high purification the currentless potential $E_{\text {mix }}$ is reported in the $0.95-1.10 \mathrm{~V}$ range $[2,4,25-27]$.

Let us introduce parameter, ${ }_{s, d} R$, to reflect a relation between surface $\mathrm{Pt}$ atoms with different valence ${ }_{s, \mathrm{~d}} \mathrm{Pt}^{\mathrm{II}} /{ }_{\mathrm{s}, \mathrm{d}} \mathrm{Pt}^{\mathrm{I}}$ in accordance with reaction (8). Estimation of parameter ${ }_{s, \mathrm{~d}} R$ value for platinum electrode surface may be performed with classical Nernst equation ${ }_{\mathrm{s}, \mathrm{d}} E_{\text {mix }}=E_{a(8)}^{*}+0.06 \lg \left({ }_{\mathrm{s}, \mathrm{d}} R\right)$, where $E_{a(8)}^{*}$ is the potential of surface oxygen-containing formation on Pt-electrodes at ${ }_{s, \mathrm{~d}} R \approx 1$. The ratio ${ }_{\mathrm{s}, \mathrm{d}} \mathrm{Pt}^{\mathrm{II}} /{ }_{\mathrm{s}, \mathrm{d}} \mathrm{Pt}^{\mathrm{I}}$ is sharply increased after treatment of Pt-electrode by anodic current (preliminary anodic oxidation) or by strong oxidizer (e.g., by concentrated $\mathrm{HNO}_{3}$ ). Correspondingly, the parameter ${ }_{s, \mathrm{~d}} R_{(8)}$ is also increased $\left({ }_{s, \mathrm{~d}} R_{(8)} \gg 1\right)$ after such treatment, and parameter ${ }_{s, \mathrm{~d}} E_{\text {mix }}$ could reach values of standard oxygen electrode of $1.23 \mathrm{~V}$ and even exceed this value. But with time artificially raised level of oxidation is decreased and gradually the usual value of parameter ${ }_{\mathrm{s}, \mathrm{d}} E_{\text {mix }}$ is set again within $0.9-1.1 \mathrm{~V}$ range. The described situation corresponds to experimental facts mentioned in review [4]. At the same time, the most favorable conditions for proceeding of ORR appear at potential $E_{\text {start }}$. This parameter corresponds to a minimal current on polarization curves in Tafel coordinates (as a rule, it is a value of about $10^{-4} \mathrm{~A} \cdot \mathrm{sm}^{-2}[2,4]$ ). As data on measurement of currentless potential ${ }_{s, d} E_{\text {mix }}$ are virtually absent in the literature, therefore to characterize sum of all polarization energy losses on oxygen electrode (shift of potential of oxygen electrode due to presence of impurities in the electrolyte, activation of ORR process, methods of preparation of electrode surface, and other phenomena) a concept of mixed uncontrolled polarization $\eta_{\text {mix }}=1.23-$ $E_{\text {start }}$ is introduced. Table 6 presents dependence of parameter $\eta_{\text {mix }}$ on structure of crystal surface (parameter $\eta_{\text {mix }}$ ) and on electrolyte nature. Values of parameter $E_{\text {start }}$ are presented for monocrystals in $\mathrm{KOH}$ solution $[7,8]$ and for polycrystalline (smooth) Pt-electrodes in $\mathrm{KOH}$ and $\mathrm{H}_{2} \mathrm{SO}_{4}$ solutions [2].

Analysis of Table 6 data leads to the following conclusions.
(1) Correlation between parameter ${ }_{s, d} N_{P t}$ and value of parameter $\eta_{\text {mix }}$ is detected on Pt monocrystal electrodes. The smallest value of parameter $\eta_{\text {mix }}$ corresponds to the densest packing of surface platinum atoms.

(2) On smooth Pt-electrodes value of parameter $\eta_{\text {mix }}$ corresponds to similar value observed on $\mathrm{Pt}(111)$ monocrystals with the densest packing of surface platinum atoms.

As mentioned above, the ConHCR concept assumes proceeding of ORR with participation of SBNO nanoclusters. The author assumes that in the state of limiting oxidation of oxygen electrode surface $\left({ }_{s, d} E=1.23 \mathrm{~V}\right)$ an appearance of nanoclusters $\mathrm{SBNO}_{1.23}$ with two surface ${ }_{s d} \mathrm{Pt}^{\mathrm{II}}$ atoms is highly probable (see Figure 2). After transition at potential $E_{\text {start }}$ into a state with an appreciable current nanoclusters $\mathrm{SBNO}_{\text {start }}$ with ${ }_{s d} \mathrm{Pt}^{\mathrm{II}}{ }_{\mathrm{s}} \mathrm{Pt}^{\mathrm{I}}$ atoms prevailed on surfaces of monocrystalline and smooth polycrystalline Pt-electrodes.

In author's opinion, the appearance of $\mathrm{SBNO}_{1.23}$ nanocluster on $\mathrm{Pt}(111)$ electrodes in alkaline media happens during stage I of 4-electron redox cycle of ORR process (see Figure 3). Experimental confirmation of concept of ORR proceeding with participation of oxygen-containing formations on surface of Pt-electrodes is provided in studies $[5,11]$. In study [5] it is determined that in pure $0.1 \mathrm{M} \mathrm{HClO}_{4}$ solution the ORR process on $\mathrm{Pt}(111)$ monocrystal electrode proceeds according to reaction (1). An addition of $\mathrm{KBr}$ solution $\left(10^{-4} \mathrm{M}\right)$ sharply changes the direction of ORR (instead of $\mathrm{H}_{2} \mathrm{O}$ molecule a molecule of hydrogen peroxide $\mathrm{H}_{2} \mathrm{O}_{2}$ is formed). A change of reaction paths correlates with change of state of monocrystal surface: introduction of $\mathrm{Br}^{-}$ions result in disappearance from cyclic voltammograms of peaks corresponding to formation of oxygen-containing structures (see Table 1). As one may see, there are CVA peaks reflecting formation of surface oxygen-containing structures in pure $\mathrm{HClO}_{4}$ on surface of $\mathrm{Pt}(111)$-electrode at $0.8-0.9 \mathrm{~V}$ interval. At the same time, this range of potentials corresponds to realization of reaction (1) with formation of water molecules. Introduction of some number of $\mathrm{Br}^{-}$ions is accompanied by disappearance of oxygen-containing structures on the Ptelectrode surface. Simultaneously potential of ORR starts to shift to $0.65 \mathrm{~V}$. This value of the potential is close to the $0.695 \mathrm{~V}$ value of the standard potential of reduction of oxygen molecule to hydrogen peroxide $[3,16]$. In publication [11] the fact that in pure $1 \mathrm{M} \mathrm{H}_{2} \mathrm{SO}_{4}$ solution at $0.90-0.95 \mathrm{~V}$ (RHE) potentials the ORR process proceeds in accordance with reaction (1) is established. An addition of $0.1 \mathrm{M} \mathrm{HCl}$ solution sharply changes the potential of start of ORR. This 


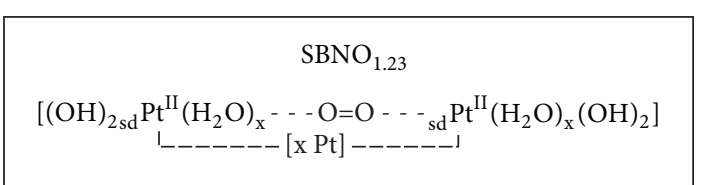

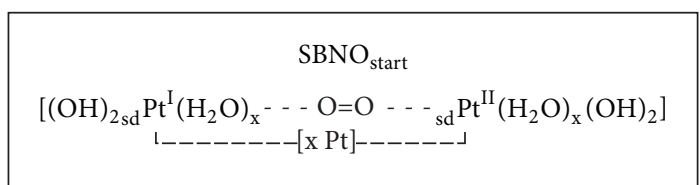

FIGURE 2: Composition of SBNO nanoclusters in state of limiting oxidation of surface of oxygen electrode $\left({ }_{s, \mathrm{~d}} E=1.23 \mathrm{~V}\right)$ and in starting state of ORR reaction $\left([x \mathrm{Pt}]\right.$ - platinum atoms from the electrode body, $\left(\mathrm{H}_{2} \mathrm{O}\right)_{x}$ - water molecules from the coordination spheres of ${ }_{\text {sd }} \mathrm{Pt}^{\mathrm{I}}$ and ${ }_{s d} \mathrm{Pt}^{\mathrm{II}}$ atoms).

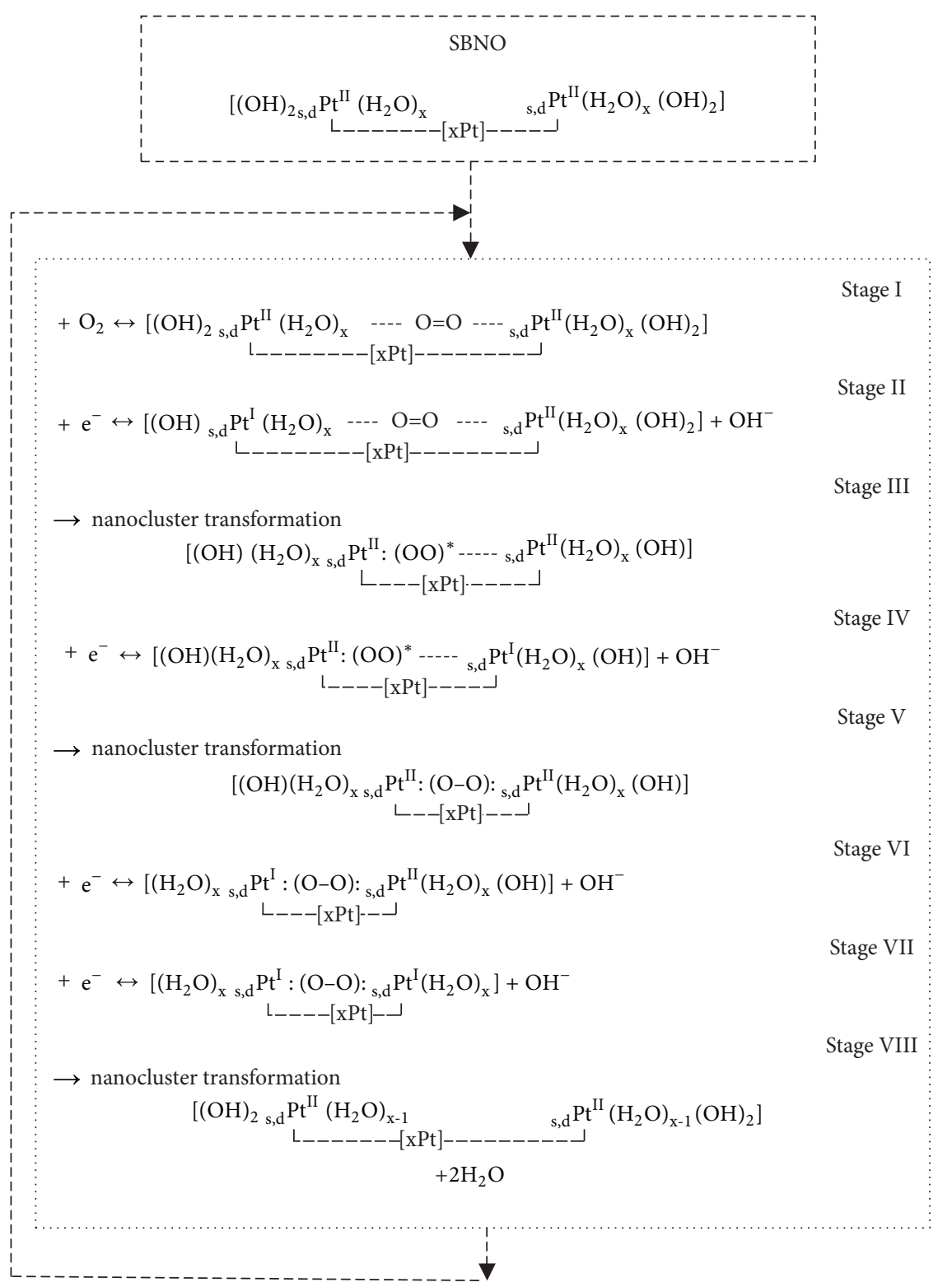

FIGURE 3: Redox cycle of ORR process in alkaline media on monocrystalline $\mathrm{Pt}(111)$ electrodes with participation of SBNO nanoclusters at potential ${ }_{s, d} E_{\text {start }}$.

parameter has a dependence on type of $\mathrm{Pt}(\mathrm{hkl})$ monocrystal. For $\mathrm{Pt}(111), \mathrm{Pt}(110)$, and $\mathrm{Pt}(100)$ monocrystals the potential of ORR start is equal to $0.720,0.690$, and $0.620 \mathrm{~V}$, correspondingly. The change of ORR start potential is accompanied by complete disappearance of CVA peaks of formation of oxygen-containing structures in the area of potential $0.70 \mathrm{~V}$ (versus RHE).

Influence of $\mathrm{I}^{-}, \mathrm{Br}^{-}$, and $\mathrm{Cl}^{-}$ions in acidic media on state of Pt-electrode surface is described in study [19]. The effect is manifested in blocking of start of the process of formation of 
oxygen-containing structures. In order of blocking efficiency the ions are placed in the $\mathrm{I}^{-}>\mathrm{Br}^{-}>\mathrm{Cl}^{-}$row. For example, concentrations at which the effect demonstrates $20 \%$ blocking have an order of $10^{-7}, 10^{-6}$, and $10^{-5} \mathrm{moll}^{-1}$, correspondingly. The study [19] reports that there is no influence of any type of anion on state of Pt-electrode surface in alkaline media.

\section{Discussion of ORR Redox Cycle on Pt-Electrodes}

The stationary potential of platinum electrode $E_{\text {stationary }}$ in acidic media has a linear dependence on logarithm of partial oxygen pressure with $60 \mathrm{mV} \mathrm{dec}^{-1}$ slope value (see review $[4,28-31])$. This experimental fact could be reflected with the following equation:

$$
E_{\text {stationary }}=E_{(p=1)}+2.3 R T(n F)^{-1} \log p,
$$

where $E_{\text {stationary }}$ is the oxygen electrode potential in the absence of current (stationary state), $E_{(p=1)}$ is the stationary (currentless) electrode potential at partial oxygen pressure $p=1 \mathrm{~atm}$, and $n$ is the quantity of electrons in electrochemical reaction. Let us note that value of $2.3 R T(n F)^{-1}$ parameter is equal to $60 \mathrm{mV}$ for $n=1$ condition. One may conclude that the electrochemical reaction proceeds with participation of a single electron. It means that stationary (currentless) electrode potential is determined by a single-electron electrochemical reaction. As already mentioned in the author's study [32], the formation of surface $\mathrm{O}_{2}{ }^{-}$structure with participation of single ${ }_{\mathrm{s}, \mathrm{d}} \mathrm{Pt}^{\mathrm{II}}$ atom in the SBNO nanocluster may be such single-electron electrochemical reaction. But probability of appearance of individual $\mathrm{O}_{2}{ }^{-}$radical on surface of platinum electrode during proceeding of ORR is very low. According to review [3] data the standard potential of $\mathrm{O}_{2}+$ $\mathrm{e}^{-}=\mathrm{O}_{2}{ }^{-}$reaction in water is equal to $-0.284 \mathrm{~V}$. The reaction $\mathrm{O}_{2}+\mathrm{e}^{-}+\mathrm{H}^{+}=\mathrm{OOH}$ with -0.053 ( $\mathrm{RHE}$ ) potential in acidic media has the higher probability of realization. Let us note that particle $(\mathrm{OO}) \mathrm{H}$ may be formally considered as hydrogen superoxide. According to the molecular orbital theory an oxygen molecule has two unpaired electrons. After bonding of a single electron to an oxygen molecule in the formed anion radical $\mathrm{O}_{2}{ }^{-}$there is still one unpaired electron. Therefore, the mentioned above reaction could be formally written as two consecutive reactions: $\mathrm{H}^{+}+\mathrm{e}^{-}=\mathrm{H}^{*}$ и $^{*} \mathrm{O}_{2}{ }^{*}+\mathrm{H}^{*}={ }^{*} \mathrm{OO}: \mathrm{H}$, where symbols “*” and “:” indicate an unpaired electron and a covalent bond with shared pair of electrons, correspondingly.

By taking into account high negative value of the standard potential one may note that for standard ORR potentials within the $0.9-1.1 \mathrm{~V}$ (versus RHE) range the concentration of hydrogen superoxide ${ }^{*} \mathrm{OO}: \mathrm{H}$ on surface of platinum electrode is a parameter with extremely small value. A higher surface content of radical structure * $(\mathrm{OO})$ could be achieved due to a contributing factor which, as noted by the author in study [32], may be a formation of nanocluster state of hydroxide/superoxide platinum with a polar covalent bond $\left[{ }^{*}(\mathrm{OO}):{ }_{\mathrm{s}, \mathrm{d}} \mathrm{Pt}{ }^{\mathrm{II}}(\mathrm{OH})\right]$.

In the ORR redox cycle in alkaline media on monocrystal $\mathrm{Pt}(111)$ electrodes (see Figure 3) this process is presented by two stages: stage II and stage III. Both stages could be combined into single reversible nanocluster reaction

$$
\begin{aligned}
{ }_{s, \mathrm{~d}} \mathrm{Pt}^{\mathrm{II}}(\mathrm{OH})_{2}+{ }^{*} \mathrm{O}_{2}{ }^{*}+\mathrm{e}^{-} \\
\left.\longleftrightarrow{ }^{*}(\mathrm{OO}):{ }_{\mathrm{s}, \mathrm{d}} \mathrm{Pt}^{\mathrm{II}}(\mathrm{OH})\right]+\mathrm{OH}^{-}
\end{aligned}
$$

The Pt(111) electrodes were chosen as an example by taking into account the following experimental facts: first, reversibility of anodic and cathodic peaks on CVA (see Table 2.); second, absence of current on the ring electrode in the rotating ring-disk electrode (RRDE) method [7, 8].

Reaction (14) corresponds to quasi-equilibrium state of oxygen electrode which, according to the experimental data, is set within $0.95-1.0 \mathrm{~V}$ (versus RHE) interval both in alkaline $[9,25,26]$ and in acidic [33] electrolytes. By taking into account that ratio of surface states ${ }_{\mathrm{s}, \mathrm{d}} \mathrm{Pt}^{\mathrm{II}}(\mathrm{OH})_{2} /$ $\left[{ }^{*}(\mathrm{OO}):{ }_{\mathrm{s}, \mathrm{d}} \mathrm{Pt}^{\mathrm{II}}(\mathrm{OH})\right]=1$, the stationary potential of quasiequilibrium oxygen electrode could be defined by the Nernst equation (13). Let us note that at stationary potentials within $0.90-1.0 \mathrm{~V}$ (versus RHE) interval reaction (14) is, practically, in equilibrium state, as the ${ }_{\mathrm{s}, \mathrm{d}} \Delta G^{*}$ parameter calculated according to (3) has values within -7 to $-16 \mathrm{~kJ} \mathrm{~mol}^{-1}$ range.

Let us note that during stage III only weakening of oxygen molecule's bonds happens in a course of reversible nanocluster chemical reaction

$$
{ }_{\mathrm{s}, \mathrm{d}} \mathrm{Pt}^{\mathrm{I}}(\mathrm{OH})+{ }^{*} \mathrm{O}_{2}{ }^{*} \longleftrightarrow\left[{ }^{*}(\mathrm{OO}):{ }_{\mathrm{s}, \mathrm{d}} \mathrm{Pt}^{\mathrm{II}}(\mathrm{OH})\right] .
$$

Break-up of first bond in an oxygen molecule happens on stage $\mathrm{V}$ during formation of platinum hydroxide peroxide $\left[(\mathrm{OH}) \mathrm{Pt}^{\mathrm{II}}:(\mathrm{O}-\mathrm{O}): \mathrm{Pt}^{\mathrm{II}}(\mathrm{OH})\right]$ in the result of irreversible nanocluster chemical reaction

$$
\begin{aligned}
& {\left[(\mathrm{OH}) \mathrm{Pt}^{\mathrm{II}}:(\mathrm{OO})^{*}---\mathrm{Pt}^{\mathrm{I}}(\mathrm{OH})\right]} \\
& \quad \longrightarrow\left[(\mathrm{OH}) \mathrm{Pt}^{\mathrm{II}}:(\mathrm{O}-\mathrm{O}): \mathrm{Pt}^{\mathrm{II}}(\mathrm{OH})\right] .
\end{aligned}
$$

In principle, ORR process may stop on stage $\mathrm{V}$ in the result of destruction of surface structures of SBNO nanoclusters

$$
\begin{aligned}
& {\left[(\mathrm{OH})_{\mathrm{s}, \mathrm{d}} \mathrm{Pt}^{\mathrm{II}}:(\mathrm{O}-\mathrm{O}):_{\mathrm{s}, \mathrm{d}} \mathrm{Pt}^{\mathrm{II}}(\mathrm{OH})\right]+\mathrm{H}_{2} \mathrm{O}+\mathrm{OH}^{-}} \\
& \longrightarrow 2{ }_{\mathrm{s}, \mathrm{d}} \mathrm{Pt}^{\mathrm{II}}(\mathrm{OH})_{2}+\mathrm{HO}_{2}{ }^{-} .
\end{aligned}
$$

Formation of $\mathrm{HO}_{2}{ }^{-}$ions in accordance with (16) may be detected with RRDE method. It was experimentally demonstrated (for example, [34-37]) that quantity of $\mathrm{HO}_{2}{ }^{-}$ ions detected on the ring depends on surface conditions of polycrystalline Pt-electrode. Preliminary anodic oxidation or cathodic reduction is accompanied by a change of ring/disk current ratio. For example, investigation of ORR in $0.1 \mathrm{M} \mathrm{NaOH}[34]$ indicated that change of anodic oxidation potential within 1.0 to $1.5 \mathrm{~V}$ (versus RHE) is accompanied by increase of ring/disk current ratio from 10 to $70 \%$. In study [35] it was reported that on Pt-electrodes oxidized at $1.2 \mathrm{~V}$ (versus RHE) potential in $\mathrm{KOH}$ solutions with concentrations within a range from 0.1 to $6 \mathrm{M}$ the ring/disk current ratio 
is unchanged parameter with about $7 \%$ value. ORR process on Pt-electrode in $0.1 \mathrm{M} \mathrm{KOH}$ for cathodic polarization of 1.1 to $-0.2 \mathrm{~V}$ (versus $\mathrm{RHE}$ ) is accompanied by ring/disk current ratio within 20-25\% interval [36]. On Pt-electrode, which was treated with preliminary cathodic reduction, the ORR process in $0.1 \mathrm{M} \mathrm{KOH}$ solution was accompanied by ring/disk current ratios within 3-5\% range [37]. Let us note that in experiments with utilization of RRDE method on monocrystalline Pt-electrodes in $0.1 \mathrm{M} \mathrm{KOH}$ solution the formation of $\mathrm{HO}_{2}{ }^{-}$ions on the ring electrode was not detected $[7,8]$.

For explanation of appearance of current on the ring during RRDE method a hypothesis is proposed that ORR processes may proceed (for example, in alkaline media) following two parallel pathways: directly to formation of $\mathrm{OH}^{-}$ions (see equation/reaction (2)) and through formation of various intermediate particles. A large number of various variants of formation of the intermediate particles are discussed in the literature (for example, in theoretical study [38] 10 different models/variants were investigated). Nevertheless, an explanation of reasons for parallel realization of two pathways of ORR process on surface of polycrystalline Pt-electrode and absence of the second pathway on monocrystalline Pt-electrodes is still missing in the literature. The author thinks that a concept of proceeding of ORR process with the very same single mechanism on all Pt-electrodes may serve as an alternative hypothesis. As experiments with utilization of RRDE method had demonstrated, on polycrystalline Pt-electrodes there are some conditions for stoppage of ORR process on stage $\mathrm{V}$ (see Figure 3). In this case the fraction of $\mathrm{HO}_{2}{ }^{-}$ions formed according to reaction (16) depends on level of perfection of structure of SBNO nanoclusters. Obviously, the perfection of structure of SBNO nanoclusters depends on the method of preparation of surface of polycrystalline Pt-electrodes for the experiment. In other words, multistage ORR process proceeds following the very same single mechanism with formation of intermediate $\left({ }^{-} \mathrm{O}-\mathrm{O}^{-}\right)$peroxide group on monocrystalline as well as on polycrystalline Pt-electrodes. The RRDE method only records an existence of stage with breakage of first bond in an oxygen molecule during some independent process. But it means that the mechanism of ORR proceeding directly following 4-electron reaction is absent. The ORR proceeds without the 4-electron reaction.

Break-up of the second bond in an oxygen molecule is realized on stage VII after two electrochemical reactions on stages VI and VII. The bond breaking happens due to irreversible nanocluster chemical reaction

$$
\left[{ }_{\mathrm{s}, \mathrm{d}} \mathrm{Pt}^{\mathrm{I}}(\mathrm{O}-\mathrm{O}):_{\mathrm{s}, \mathrm{d}} \mathrm{Pt}^{\mathrm{I}}\right]+2 \mathrm{H}_{2} \mathrm{O} \longrightarrow 2{ }_{\mathrm{s}, \mathrm{d}} \mathrm{Pt}^{\mathrm{II}}(\mathrm{OH})_{2}
$$

The redox cycle scheme in Figure 3 reflects ORR with slowed stage of ConHCR. Heterogeneous chemical reaction of oxidation by the molecular oxygen of electrochemically reduced surface ${ }_{s, d} \mathrm{Pt}$ atoms has several stages. The author believes that reaction (14) is a limiting factor for entire ConHCR. In reaction (14) nanocluster surface transitional state (NcSTS) with participation of ${ }_{\mathrm{s}, \mathrm{d}} \mathrm{Pt}$ atoms and an oxygen molecule is formed for the first time. Formed NcSTS creates conditions for transfer of first electron from ${ }_{\mathrm{s}, \mathrm{d}} \mathrm{Pt}$ atoms into an oxygen molecule; it results in formation of $\left[{ }^{*}(\mathrm{OO}):{ }_{\mathrm{s}, \mathrm{d}} \mathrm{Pt}^{\mathrm{II}}(\mathrm{OH})\right]$ structure. Formally this process may be considered as slowed transfer of first electron. Theoretical aspects of slowed transfer of first electron concept were multiple times discussed in the literature (e.g., [21, 38-43]). The basis of slowed transfer of first electron concept is a consideration that electron is transferred to an oxygen molecule from neutral surface Pt atom.

Quasi-equilibrium state of oxygen Pt-electrode is characterized by a fact that effect of unchanged potentials is observed in alkaline media during change of current from $10^{-7}$ to $10^{-6} \mathrm{~A} \mathrm{sm}^{-2}[9,25,44]$. The provided above currents may be considered as exchange current of reaction (14). An analogous experimental effect is also observed in acidic media $[33,44]$. But in this case reaction (14) shall be transformed by accounting for a change of composition and structure of SBNO nanoclusters in acidic media [45]. Peculiarity of the cited above experiments is in utilization of specific methods of measurements, as described in study [9]. Each experiment was started with several alternations of anodic and cathodic polarization at potentials of 2.0 and $0.05 \mathrm{~V}$ (versus RHE), correspondingly. After final cathodic polarization the cycle of measurements of ORR parameters was performed (realization of "oxide-free" state $[28,29]$ ). By accounting for thermodynamic probability of proceeding of reactions (10) and (11) the author concludes that the more correct definition of the achieved state should be "oxide fresh" state.

Let us note that exchange currents on Pt-electrode, according to studies $[26,33]$, depend on temperature. This experimental fact and the change of activation energy of ORR at $0.8 \mathrm{~V}$ potential $[26,33]$ should become a subject of independent research efforts.

Let us also note that the concept of proceeding of ORR with slowed stage of ConHCR allows us an understanding of the experimental fact of dependence of angle of polarization curves in alkaline media in Tafel coordinates (coefficient $b$ ) on type of Pt-electrode, current characteristics, and sizing of particles of disperse platinum. At low values of the current the coefficient $b$ is equal to $60 \mathrm{mV}$ per dec on all types of Ptelectrodes (smooth platinum [26, 27, 35], disperse platinum on carbon substrate [46]). At high current values the various values of coefficient $b$ were reported: $120 \mathrm{mV}$ per dec [26, 27,46 ] and 200-300 $\mathrm{mV}$ per dec range [35]. On electrodes with platinum nanoparticles on disperse carbon [47] we detected dependence of coefficient $b$ from size of platinum nanoparticles. An increase of platinum nanoparticles size from 3 to $24 \mathrm{~nm}$ resulted in corresponding decrease of the coefficient $b$ from 80 to $65 \mathrm{mV}$ per dec.

Dependence of currentless (stationary) potential of oxygen electrode on oxygen pressure (see (13)) was observed in solutions of various electrolytes: $\mathrm{KOH}[31], \mathrm{H}_{2} \mathrm{SO}_{4}[30,31$, 48], and $\mathrm{HClO}_{4}[28,29]$. This experimental fact indicates a single-electron character of reaction which defines the nature of currentless potential of platinum oxygen electrode. In alkaline media, it may be a reaction of formation of platinum superoxide [49]. A process of occurrence of transitional state based on platinum superoxide would be the slowed stage of reaction (14), as well as of the whole ORR on Pt-electrodes 
in any alkaline solution. A validity of this assumption is confirmed by identical slopes (about $60 \mathrm{mV} / \mathrm{dec}$ ) of polarization curves in Tafel coordinates for various alkaline solutions (for example, $\mathrm{KOH}$ [31], $\mathrm{NaOH}$ [9], $\mathrm{K}_{2} \mathrm{CO}_{3}$ [18], $\mathrm{K}_{2} \mathrm{~B}_{4} \mathrm{O}_{7}$ [9], and $\mathrm{KF}$ [9]). In terms of the concept of electrochemical reaction with slowed stage of ConHCR, it means energetic homogeneity of electrode surface according to Temkin at low current values.

\section{Conclusion}

Four specialized parameters ${ }_{s, \mathrm{~d}} \Delta G^{*}{ }_{\mathrm{s}, \mathrm{d}} \mathrm{N}_{\mathrm{pt}}, \eta_{\text {mix }}$, and ${ }_{\mathrm{s}, \mathrm{d}} R$ (Gibbs energy of a process with participation of surface platinum atoms, ${ }_{s, d} \mathrm{Pt}$; packing density of ${ }_{\mathrm{s}, \mathrm{d}} \mathrm{Pt}$ atoms; uncontrolled activation polarization; level of surface oxidation as a ratio ${ }_{s, \mathrm{~d}} \mathrm{Pt}^{\mathrm{II}} /_{\mathrm{s}, \mathrm{d}} \mathrm{Pt}^{\mathrm{I}}$ atoms, correspondingly) were used for characterization of surfaces of monocrystalline and polycrystalline Pt-electrodes.

Parameter ${ }_{s, \mathrm{~d}} \Delta G^{*}$ is the thermodynamic characteristic of proceeding of electrochemical and chemical reactions with participation of surface ${ }_{s, \mathrm{~d}} \mathrm{Pt}$ atoms. Parameter ${ }_{\mathrm{s}, \mathrm{d}} \Delta G^{*}$ was calculated from literature experimental data on cyclic voltammograms on $\mathrm{Pt}(\mathrm{hkl})$ monocrystals and polycrystalline Pt-electrodes. The parameter was determined for surface oxygen-containing structures (which serve as building blocks for formation of SBNO nanoclusters and therefore define the structure of SBNO nanoclusters) in nitrogen atmosphere, as well as in molecular oxygen atmosphere.

Parameter ${ }_{s, d} \mathrm{~N}_{\mathrm{Pt}}$ (quantity of ${ }_{\mathrm{s}, \mathrm{d}} \mathrm{Pt}$ atoms per $1 \mathrm{~nm}^{2}$ of Ptelectrode surface) characterizes packing density of Pt atoms on surface of $\mathrm{Pt}(\mathrm{hkl})$ monocrystals. The densest packing of ${ }_{s, \mathrm{~d}} \mathrm{Pt}\left({ }_{s, \mathrm{~d}} \mathrm{~N}_{\mathrm{Pt}}=17\right)$ atoms is determined for Pt(111) monocrystal. Monocrystals $\mathrm{Pt}(110)$ and $\mathrm{Pt}(100)$ are characterized by less dense packing of surface platinum atoms $\left({ }_{s, \mathrm{~d}} \mathrm{~N}_{\mathrm{Pt}}=9\right.$ and 13, correspondingly). For monocrystalline Pt-electrodes an increase of ${ }_{s, d} N_{P t}$ parameter correlates with decrease of ${ }_{s, \mathrm{~d}} \Delta G^{*}$ parameter. The value of ${ }_{\mathrm{s}, \mathrm{d}} \Delta G^{*}$ parameter for polycrystalline Pt-electrodes is close to value of ${ }_{s, \mathrm{~d}} \Delta G^{*}$ parameter for $\mathrm{Pt}(111)$ monocrystals with the most dense packing of surface Pt atoms.

Parameter $\eta_{\text {mix }}=1.23-E_{\text {start }}$ characterizes all types of polarization effects (e.g., shift of oxygen electrode potential due to presence of impurities in electrolyte, nature of electrolyte, activation of ORR process, and methods of preparation of electrode surface). The correlation between ${ }_{\mathrm{s}, \mathrm{d}} \mathrm{N}_{\mathrm{Pt}}$ and $\eta_{\text {mix }}$ parameters was detected. The smallest value of parameter $\eta_{\text {mix }}$ corresponds to the densest packing of surface platinum atoms of $\mathrm{Pt}(111)$ monocrystal. On smooth Pt-electrodes value of parameter $\eta_{\text {mix }}$ corresponds to value observed on $\mathrm{Pt}$ monocrystals with the densest packing of surface platinum atoms.

Parameter ${ }_{s, \mathrm{~d}} R$ characterizes the ratio of ${ }_{\mathrm{s}, \mathrm{d}} \mathrm{Pt}^{\mathrm{II}} /{ }_{\mathrm{s}, \mathrm{d}} \mathrm{Pt}^{\mathrm{I}}$ atoms on surface of Pt-electrodes and as such reflects level of oxidation of platinum surface. In the stationary state ${ }_{s, \mathrm{~d}} \mathrm{Pt}^{\mathrm{II}}$ atoms prevail over ${ }_{s, \mathrm{~d}} \mathrm{Pt}^{\mathrm{I}}$ atoms on surface of Pt-electrodes $\left({ }_{s, \mathrm{~d}} R \gg 1\right)$. At potential of start of ORR, the quantity of ${ }_{s, \mathrm{~d}} \mathrm{Pt}^{\mathrm{I}}$ atoms increases and value of ${ }_{\mathrm{s}, \mathrm{d}} R$ parameter sharply changes $\left({ }_{s, d} R \approx 1\right)$. Such situation was interpreted as activation of SBNO nanoclusters and appearance of conditions for proceeding of ORR.

Analysis of role of oxygen-containing nanoclusters in proceeding of ORR on Pt-electrodes was conducted on the basis of concept of electrochemical process with slowed stage of consecutive heterogeneous chemical reaction. Under this concept the main factor determining the ORR characteristics is energetic inhomogeneity of electrode surface according to Temkin. New concept, according to which EIES is determined by the Gibbs energy of formation of OSS $\left(_{s, \mathrm{~d}} \Delta G^{*}\right.$ parameter) with participation of surface platinum atoms, ${ }_{s, \mathrm{~d}} \mathrm{Pt}$, was formulated. Analysis of determined values of ${ }_{\mathrm{s}, \mathrm{d}} \Delta G^{*}$ parameter resulted in the following conclusions. First, the OSS based on ${ }_{s, d} \mathrm{Pt}^{\mathrm{I}}(\mathrm{OH})$ and ${ }_{\mathrm{s}, \mathrm{d}} \mathrm{Pt}^{\mathrm{II}}(\mathrm{OH})_{2}$ hydroxides are formed as a result of chemical reaction of oxidation by the molecular oxygen of ${ }_{s, \mathrm{~d}} \mathrm{Pt}$ atoms in alkaline medium. Second, in a currentless state the OSS based on ${ }_{s, d} \mathrm{Pt}^{\mathrm{II}}(\mathrm{OH})_{2}$ hydroxide predominate on the surface of Pt-electrodes; correspondingly SBNO nanoclusters based on ${ }_{s, d} \mathrm{Pt}^{\mathrm{II}}$ also predominate on the surface of Pt-electrodes. Third, at ORR potentials the EIES of polycrystalline Pt-electrodes is a result of combination of characteristics of multiple different $\mathrm{Pt}(\mathrm{hkl})$ monocrystals.

A correlation between EIES according to Temkin and packing density of ${ }_{s, \mathrm{~d}} \mathrm{Pt}$ atoms was determined. $\mathrm{Pt}(111)$ monocrystals have the most dense packing of ${ }_{s, \mathrm{~d}} \mathrm{Pt}$ atoms. Therefore, such crystals are characterized by the energetic homogeneity of electrode surface according to Temkin. The high level of energetic inhomogeneity of electrode surface of $\mathrm{Pt}(110)$ and $\mathrm{Pt}(100)$ monocrystals is caused by low packing density of ${ }_{s, \mathrm{~d}} \mathrm{Pt}$ atoms and resulting direct influence of $\mathrm{Pt}$ atoms from a subsurface layer on energetic characteristics of the electrode surface. In turn, the surface of polycrystalline platinum electrodes is characterized by complex mosaic of $\mathrm{Pt}(\mathrm{hkl})$ monocrystals and corresponding complex EIES character.

The redox cycle of multistage ORR in alkaline media with participation of SBNO nanoclusters and slowed stage of ConHCR was proposed. The concept according to which the stage of formation of primary nanocluster transitional state determines rate of the whole ORR process was substantiated. Formation of platinum superoxide also happens during this stage.

\section{Data Availability}

All data supporting the results and conclusions of this research work are included in the paper's tables and figures; therefore, such data are unavailable anywhere else.

\section{Conflicts of Interest}

The author declares that there are no conflicts of interest regarding the publication of this manuscript.

\section{Acknowledgments}

The author would like to thank Dr. Aleksey M. Trunov for discussions of the manuscript's draft. 


\section{References}

[1] A. J. Appleby, "Electrocatalysis of aqueous dioxygen reduction," Journal of Electroanalytical Chemistry, vol. 357, p. 117, 1993.

[2] M. R. Tarasevich and E. I. Khrushcheva, Kinetics of Complex Electrochemical Reactions, Nauka, Moscow, Russia, 1981, in Russian.

[3] M. R. Tarasevich, A. Sadkowski, and E. Yeager, "Oxygen electrochemistry," in Comprehensive Treatise of Electrochemistry, B. E. Conway, J. O'M. Bockris, E. Yeager, U. M. S. Kahn, and R. E. White, Eds., Plenum Press, New York, NY, USA, 1983.

[4] A. Damjanovic, "Mechanism and kinetics of oxygen electrode," in Modern Aspect of Electrochemistry, J. O’M. Bockris and B. E. Conway, Eds., Plenum Press, New York, NY, USA, 1969.

[5] N. M. Markovic, H. A. Gasteiger, B. N. Grgur, and P. N. Ross, "Oxygen reduction reaction on Pt(111): effects of bromide," Journal of Electroanalytical Chemistry, vol. 467, p. 157, 1999.

[6] N. M. Markovic, H. A. Gasteiger, and P. N. Ross Jr., "Oxygen reduction on platinum low-index single-crystal surfaces in alkaline solution: rotating ring disk $\mathrm{Pt}(\mathrm{hkl})$ studies," The Journal of Physical Chemistry, vol. 100, p. 6715, 1996.

[7] T. J. Schmidt, V. Stamenkovic, P. N. Ross Jr., and N. M. Markovic, "Temperature dependent surface electrochemistry on Pt single crystals in alkaline electrolyte. Part 3. The oxygen reduction reaction," Physical Chemistry Chemical Physics, vol. 5, p. 400, 2003.

[8] T. J. Schmidt, V. Stamenkovic, M. Arenz, N. M. Markovic, and P. N. Ross Jr., "Oxygen electrocatalysis in alkaline electrolyte: $\mathrm{Pt}(\mathrm{hkl}), \mathrm{Au}(\mathrm{hkl})$ and the effect of Pd-modification," Electrochimica Acta, vol. 47, p. 3765, 2002.

[9] D. B. Sepa, M. V. Vojnovic, and A. Damjanovic, "Kinetics and mechanism of $\mathrm{O}_{2}$ reduction at $\mathrm{Pt}$ in alkaline solutions," Electrochimica Acta, vol. 25, p. 1491, 1980.

[10] V. S. Bagotskii and M. R. Tarasevich, "Oxygen adsorption on platinum and platinum metals. Part I. Investigation of the adsorption mechanism by the potentiodynamic method," Journal of Electroanalytical Chemistry, vol. 101, p. 1, 1979.

[11] F. El Kadiri, R. Faure, and R. Durand, "Electrochemical reduction of molecular oxygen on platinum single crystals," Journal of Electroanalytical Chemistry, vol. 301, p. 177, 1991.

[12] A. Trunov, "Analysis of oxygen reduction reaction pathways on $\mathrm{Co}_{3} \mathrm{O}_{4}, \mathrm{NiCo}_{2} \mathrm{O}_{4}, \mathrm{Co}_{3} \mathrm{O}_{4}-\mathrm{Li}_{2} \mathrm{O}, \mathrm{NiO}, \mathrm{NiO}-\mathrm{Li}_{2} \mathrm{O}, \mathrm{Pt}$, and $\mathrm{Au}$ electrodes in alkaline medium," Electrochimica Acta, vol. 105, p. 506, 2013.

[13] A. M. Trunov, "On the mechanism of oxygen reduction on single crystal and polycrystalline Pt electrodes in alkaline media," Russian Journal of Electrochemistry, vol. 51, p. 332, 2015.

[14] A. J. Appleby, "Bronsted relationship in electrocatalysis," Surface Science, vol. 27, p. 225, 1971.

[15] A. J. Appleby, "Electrocatalysis," in Comprehensive Treatise of Electrochemistry, B. E. Conway, J. O’M. Bockris, E. Yeager, U. M. S. Kahn, and R. E. White, Eds., vol. 7, Plenum Press, New York, NY, USA, 1983.

[16] A. M. Sukhotin, Ed., Electrochemistry Handbook, Chemistry, Leningrad, Russia, 1981.

[17] B. P. Nikolskiy, Ed., Chemist's Handbook, vol. 1, Goschimisdat, Leningrad, Russia, 1962.

[18] K. A. Striebel, F. R. McLarnon, and E. J. Cairns, "Oxygen reduction on $\mathrm{Pt}$ in aqueous $\mathrm{K}_{2} \mathrm{CO}_{3}$ and $\mathrm{KOH}$," Journal of the Electrochemical Society, vol. 137, p. 3351, 1990.
[19] B. E. Conway, "Electrochemical oxide film formation at noble metals as a surface-chemical process," Progress in Surface Science, vol. 49, p. 331, 1995.

[20] H. Angerstein-Kozlovska, B. E. Conway, and W. B. A. Sharp, "The real condition of electrochemically oxidized platinum surfaces. Part 1. Resolution of component processes," Journal of Electroanalytical Chemistry, vol. 431, p. 9, 1973.

[21] E. Yeager, "Dioxygen electrocatalysis: mechanisms in relation to catalyst structure," Journal of Molecular Catalysis, vol. 38, p. 5,1986 .

[22] Li. Tao and P. B. Balbuena, "Oxygen reduction on a platinum clusters," Chemical Physics Letters, vol. 367, p. 439, 2003.

[23] J. P. Hoare, "The normal oxygen potential on bright platinum," Journal of the Electrochemical Society, vol. 110, p. 1019, 1963.

[24] J. P. Hoare, "Rest potential in the platinum-oxygen-acid system," Journal of the Electrochemical Society, vol. 109, p. 858, 1962.

[25] A. Damjanovic, A. Dey, and J. O’M. Bockris, "Kinetics of oxygen evolution and dissolution on platinum electrodes," Electrochimica Acta, vol. 11, p. 791, 1966.

[26] D. B. Sepa, M. V. Vojnovic, Lj. M. Vracar, and A. Damjanovic, "Apparent enthalpies of activation of electrodic oxygen reduction at platinum in different current density regions - II. Alkaline solution," Electrochimica Acta, vol. 31, p. 97, 1986.

[27] M. D. Obradovic, B. N. Grgur, and Lj. M. Vracar, "Adsorption of oxygen containing species and their effect on oxygen reduction on $\mathrm{Pt}_{3}$ Co electrode," Journal of Electroanalytical Chemistry, vol. 548 , p. 69, 2003.

[28] H. Wroblowa, M. L. B. Rao, A. Damjanovic, and J. O’M. Bockris, "Adsorption and kinetics at platinum electrodes in the presence of oxygen at zero net current," Journal of Electroanalytical Chemistry, vol. 15, p. 139, 1967.

[29] A. Damjanovic and V. Brusic, "Electrode kinetics of oxygen reduction on oxide-free platinum electrodes," Electrochimica Acta, vol. 12, p. 615, 1967.

[30] S. Schuldiner and R. M. Roe, “The Pt/O $\mathrm{O}_{2}$ electrode in sulfuric acid solution," Journal of the Electrochemical Society, vol. 110, p. $1142,1963$.

[31] V. I. Shepelev, M. R. Tarasevich, and R. X. Burshtain, "Influence of pressure on oxygen ionization on platinum electrode. Oxygen reduction on oxidised and reduced electrode in acidic and alkiline solutions," Elektrokhimiya, vol. 7, p. 999, 1971 (Russian).

[32] A. M. Trunov, "Analysis of nature of stationary oxygen potential on Pt electrodes in alkaline media," in Theory and Practice of Contemporary Electrochemical Manufactures, p. 14, Polytechnic University Press, Saint Petersburg, Russia, 2014.

[33] D. B. Sepa, M. V. Vojnovic, Lj. M. Vracar, and A. Damjanovic, "Apparent enthalpies of activation of electrodic oxygen reduction at platinum in different current density regions - II. Acid solution," Electrochimica Acta, vol. 31, p. 91, 1986.

[34] V. I. Lukyanycheva, A. V. Yuzhania, M. R. Tarasevich, N. A. Shumilova, and V. S. Bagotskii, "Kinetics of reduction of molecular oxygen at preliminary oxidized platinum electrode in alkaline solution," Elektrokhimiya, vol. 13, p. 506, 1977 (Russian).

[35] S. M. Park, S. Ho, S. Aruliah et al., "Electrochemical reduction of oxygen at platinum electrodes in $\mathrm{KOH}$ solutions. Temperature and concentration effects," Journal of the Electrochemical Society, vol. 133, p. 1641, 1986.

[36] N. R. K. Vilambi and E. J. Taylor, "Quantitative detection of peroxide formation during oxygen reduction on platinum in alkaline media," Electrochimica Acta, vol. 34, p. 1449, 1989. 
[37] A. Damjanovic, M. A. Genshaw, and J. O’M. Bockris, “The mechanism of oxygen reduction at platinum in alkaline solutions with special reference to $\mathrm{H}_{2} \mathrm{O}_{2}$, Journal of the Electrochemical Society, vol. 114, p. 1107, 1967.

[38] K. L. Hsueh, D. T. Chin, and S. Srinivasan, "Electrode kinetics of oxygen reduction. A theoretical and experimental analysis of the rotating ring-disc electrode method," Journal of Electroanalytical Chemistry, vol. 153, p. 79, 1983.

[39] J. O'M. Bocris and R. Abdu, "A theoretical study of the electrochemical reduction of oxygen," Journal of Electroanalytical Chemistry, vol. 448, p. 189, 1998.

[40] C. Hartnig and M. T. M. Koper, "Molecular dynamics simulation of the first electron transfer step in the oxygen reduction reaction," Journal of Electroanalytical Chemistry, vol. 532, p. 165, 2002.

[41] A. Ignaczak, W. Schmickler, and S. Bartenschlager, "Electrochemical reduction of the $\mathrm{O}_{2}$ molecule to the $\mathrm{O}_{2}^{-}$radical ion A theoretical approach," Journal of Electroanalytical Chemistry, vol. 586, p. 297, 2006.

[42] A. B. Anderson, "Volcano plots and effective reversible potentials for oxygen electroreduction," Electrocatalysis, vol. 3, p. 176, 2012.

[43] A. Anderson, R. Jinnouchi, and J. Uddin, "Effective reversible potentials and onset potentials for $\mathrm{O}_{2}$ electroreduction on transition metal electrodes: theoretical analysis," Journal of Physical Chemistry C, vol. 117, p. 41, 2013.

[44] D. B. Sepa, M. V. Vojnovic, and A. Damjanovic, "Reaction intermediates as a controlling factor in the kinetics and mechanism of oxygen reduction at platinum electrodes," Electrochimica Acta, vol. 26, p. 781, 1981.

[45] A. M. Trunov, "On oxygen reduction reaction at platinum electrodes in alkaline media," in Proceedings of the V Conference "Contemporary Methods of Theoretical and Experimental Electrochemistry”, p. 181, Ivanovo, Russia, 2013 (Russian).

[46] F. H. B. Lima, M. L. Calegaro, and E. A. Ticianelli, "Electrocatalytic activity of dispersed platinum and silver alloys and manganese oxides for the oxygen reduction in alkaline electrolyte," Russian Journal of Electrochemistry, vol. 42, p. 1283, 2006.

[47] L. Genies, R. Faure, and R. Durand, "Electrochemical reduction of oxygen on platinum nanoparticles in alkaline media," Electrochimica Acta, vol. 44, p. 1317, 1998.

[48] T. B. Warner and S. Schuldiner, "Potential of a platinum electrode at low partial pressures of hydrogen or oxygen," Journal of the Electrochemical Society, vol. 112, p. 853, 1965.

[49] A. M. Trunov, "Analysis of role of oxygen-containing structures on Pt electrode surface in oxygen reduction reaction," in Proceedings of the VII Conference "Contemporary Methods of Theoretical and Experimental Electrochemisty", p. 188, Ivanovo, Russia, 2015 (Russian). 

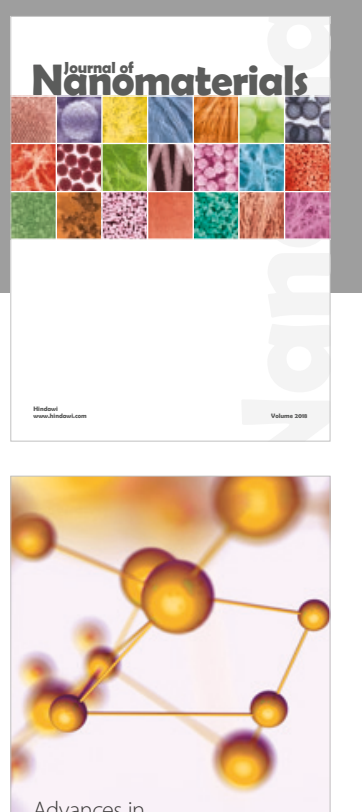

Physical Chemistry
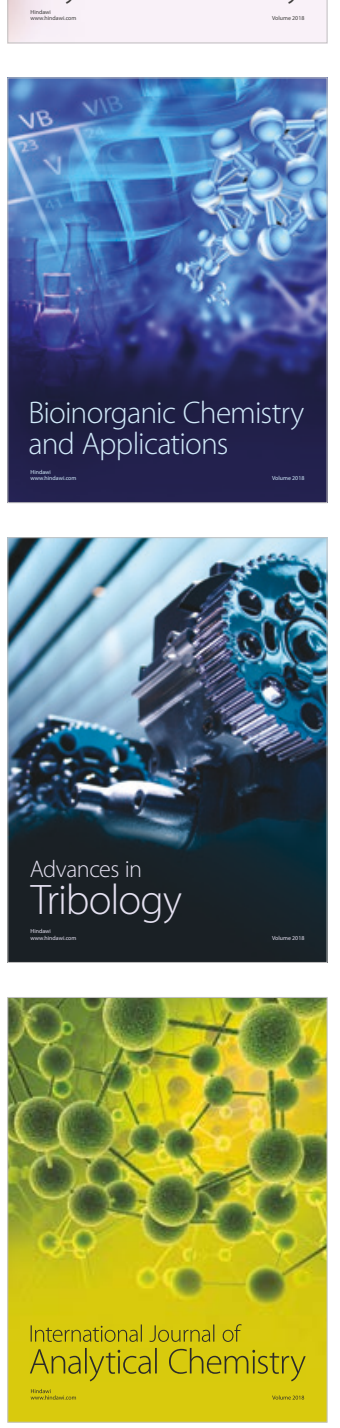

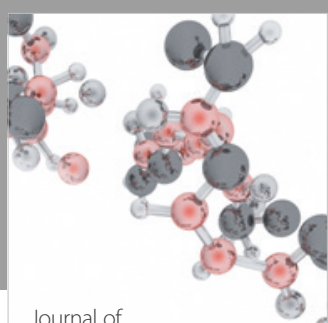

Analytical Methods

in Chemistry

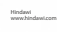

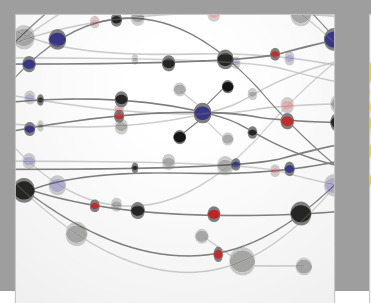

The Scientific World Journal

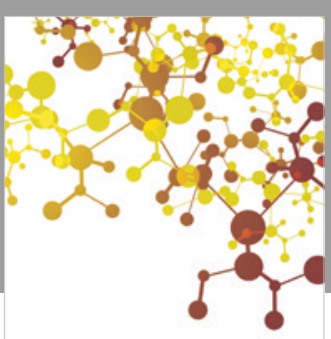

Journal of

Applied Chemistry
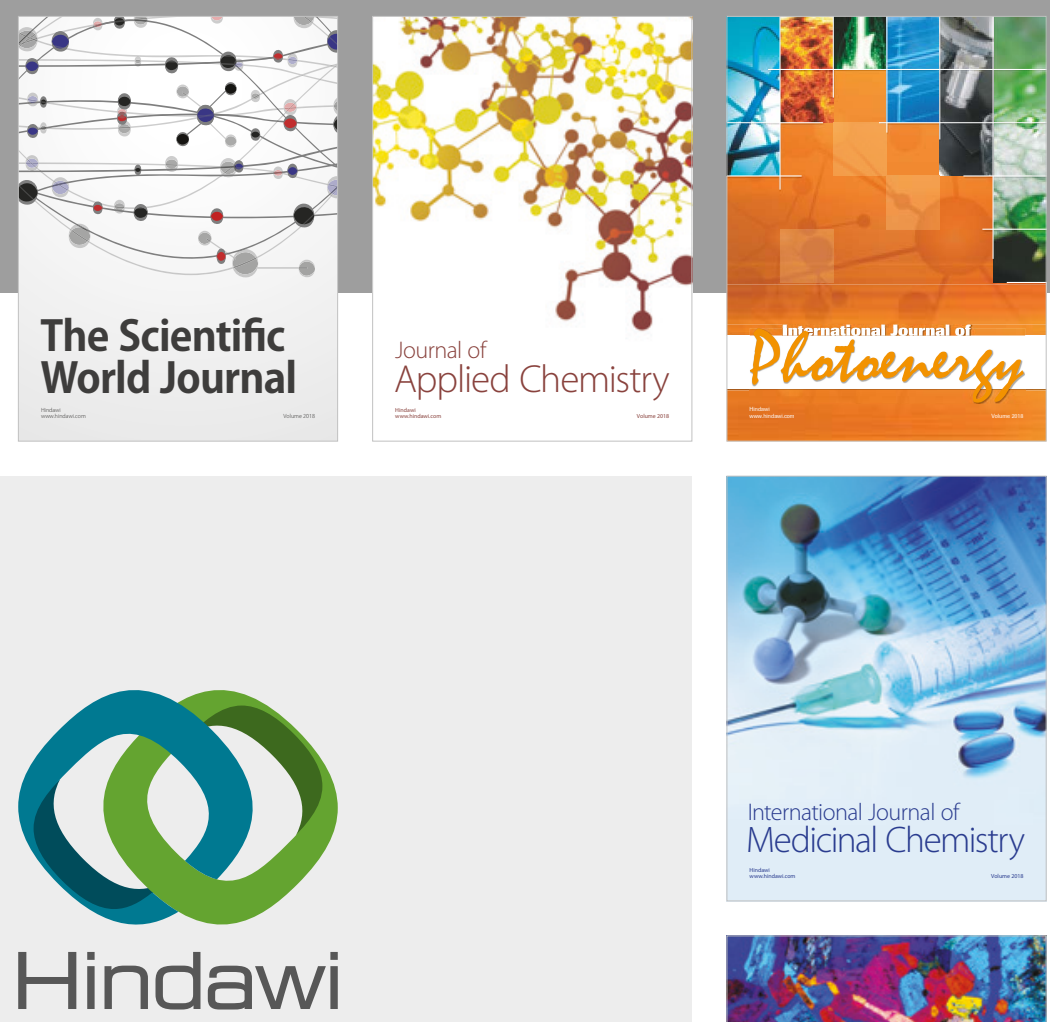

Submit your manuscripts at

www.hindawi.com
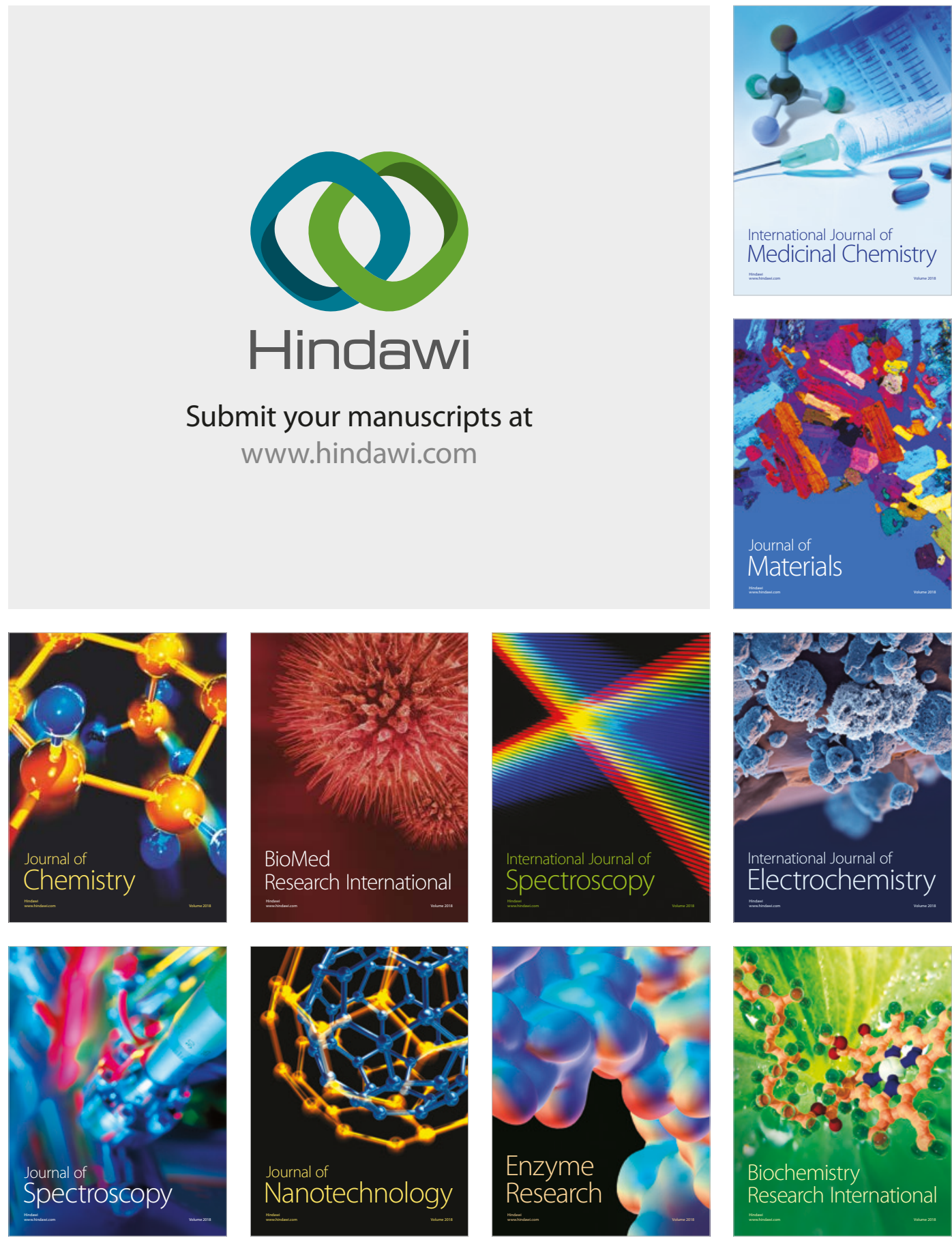
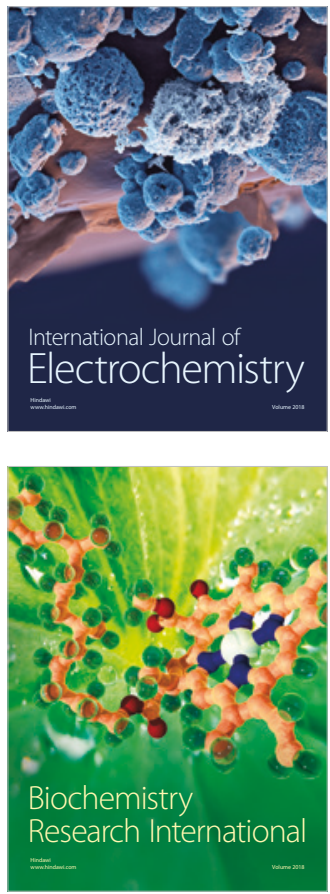